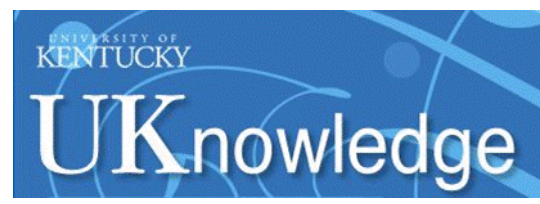

University of Kentucky

UKnowledge

\title{
Effects of Repeated Cue Exposure on Cannabis Craving
}

Jessica S. Fogel

University of Kentucky, js.fogel@gmail.com

Right click to open a feedback form in a new tab to let us know how this document benefits you.

\section{Recommended Citation}

Fogel, Jessica S., "Effects of Repeated Cue Exposure on Cannabis Craving" (2015). Theses and Dissertations--Psychology. 68.

https://uknowledge.uky.edu/psychology_etds/68

This Master's Thesis is brought to you for free and open access by the Psychology at UKnowledge. It has been accepted for inclusion in Theses and Dissertations--Psychology by an authorized administrator of UKnowledge. For more information, please contact UKnowledge@lsv.uky.edu. 


\section{STUDENT AGREEMENT:}

I represent that my thesis or dissertation and abstract are my original work. Proper attribution has been given to all outside sources. I understand that I am solely responsible for obtaining any needed copyright permissions. I have obtained needed written permission statement(s) from the owner(s) of each third-party copyrighted matter to be included in my work, allowing electronic distribution (if such use is not permitted by the fair use doctrine) which will be submitted to UKnowledge as Additional File.

I hereby grant to The University of Kentucky and its agents the irrevocable, non-exclusive, and royalty-free license to archive and make accessible my work in whole or in part in all forms of media, now or hereafter known. I agree that the document mentioned above may be made available immediately for worldwide access unless an embargo applies.

I retain all other ownership rights to the copyright of my work. I also retain the right to use in future works (such as articles or books) all or part of my work. I understand that I am free to register the copyright to my work.

\section{REVIEW, APPROVAL AND ACCEPTANCE}

The document mentioned above has been reviewed and accepted by the student's advisor, on behalf of the advisory committee, and by the Director of Graduate Studies (DGS), on behalf of the program; we verify that this is the final, approved version of the student's thesis including all changes required by the advisory committee. The undersigned agree to abide by the statements above.

Jessica S. Fogel, Student

Dr. Joshua A. Lile, Major Professor

Dr. Mark T. Filmore, Director of Graduate Studies 


\title{
EFFECTS OF REPEATED CUE EXPOSURE ON CANNABIS CRAVING
}

\section{THESIS}

A thesis submitted in partial fulfillment of the requirements for the degree of Master of Science in the College of Arts and Sciences at the University of Kentucky

\author{
By \\ Jessica S. Fogel \\ Lexington, Kentucky \\ Director: Joshua Lile, Professor of Psychology \\ Lexington, Kentucky \\ 2015
}

Copyright (C) Jessica S. Fogel 2015 


\section{ABSTRACT OF THESIS}

\section{EFFECTS OF REPEATED CUE EXPOSURE ON CANNBIS CRAVING}

Craving is a key element of the cannabis withdrawal syndrome that has been associated with continued use and relapse. Although cue-induced cannabis craving has been established in single laboratory sessions, procedures to sustain craving over multiple sessions are needed. The purpose of the present study was to determine if cue-induced craving responses could be elicited in the same subjects across multiple sessions. It was hypothesized that exposure to cannabis cues would produce more robust craving responses than exposure to neutral cues and that elicited craving responses will be sustained across multiple cue exposures. Five experimental cue exposure sessions (1 neutral and 4 cannabis) were conducted. Craving was assessed with the Marijuana Craving Questionnaire (MCQ) Short Form, Visual Analog Scale (VAS), Subject-Rated Physiological Questionnaire, blood pressure, and heart rate. Results revealed significant effects of initial cannabis cue exposure on VAS craving responses and Subject-Rated Physiological measures relative to the neutral cue exposure condition. No significant differences were found on MCQ composite scores or physiological measures. Craving responses following initial cannabis cue exposure were not maintained across sessions. There is a need for a better understanding of the factors that contribute to continued drug use despite quit attempts.

KEYWORDS: Cannabis, Cue-Exposure, Craving, Subjective Effects

Jessica S. Fogel

May 27, 2015 


\section{EFFECTS OF REPEATED CUE EXPOSURE ON CANNABIS CRAVING}

\section{By}

Jessica S. Fogel

Dr. Joshua A. Lile Director of Thesis

Dr. Mark T. Filmore Director of Graduate Studies 


\section{TABLE OF CONTENTS}

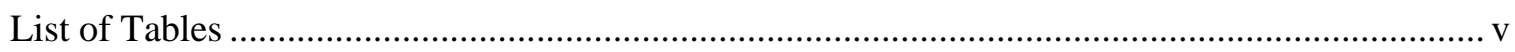

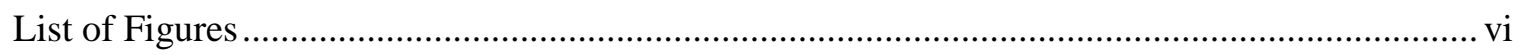

Chapter One: Significance and Background ...................................................................... 1

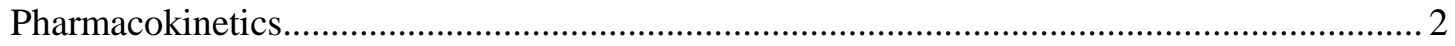

Mechanism of Action and Neurological Correlates ............................................................. 3

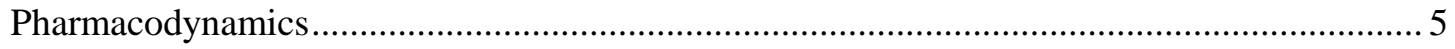

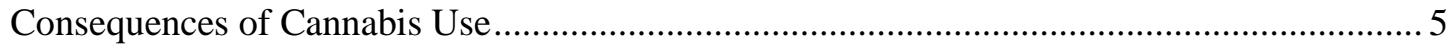

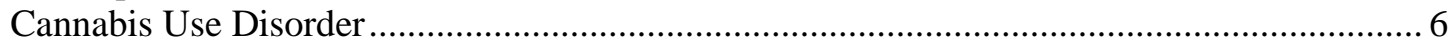

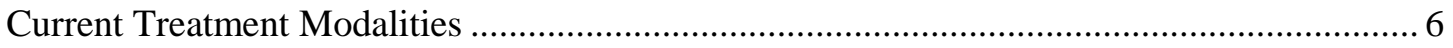

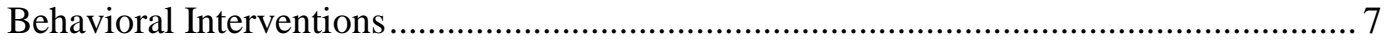

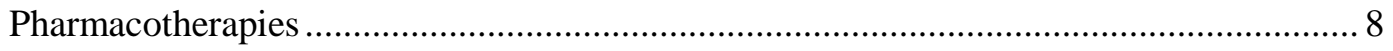

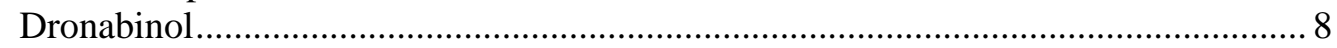

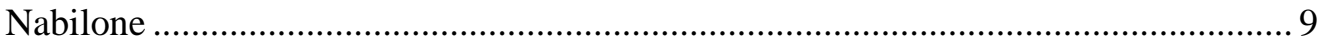

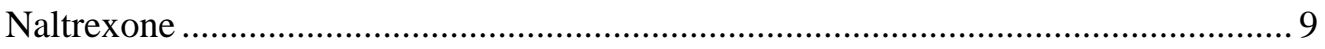

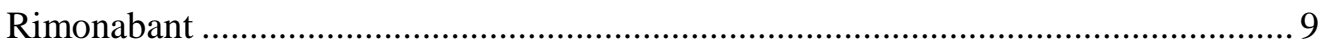

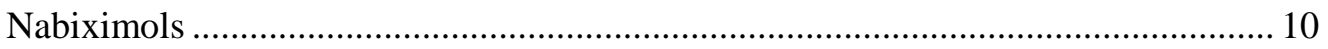

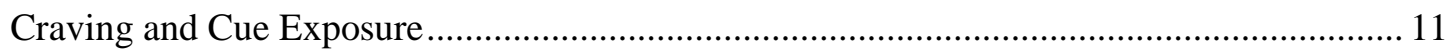

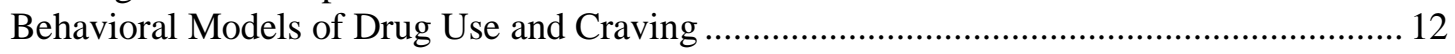

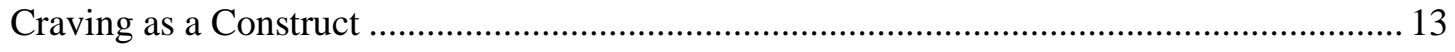

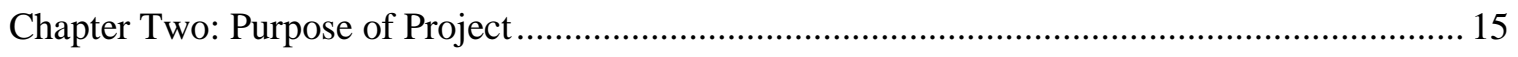

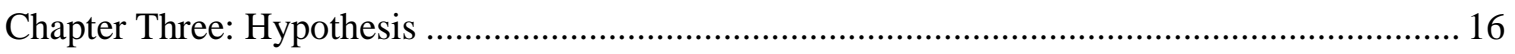

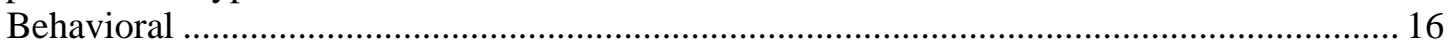

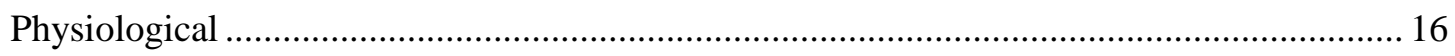

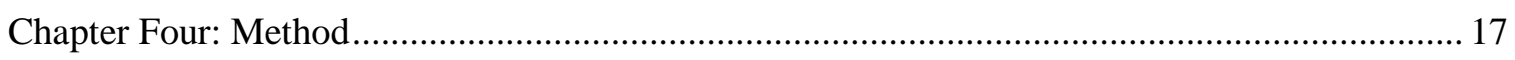

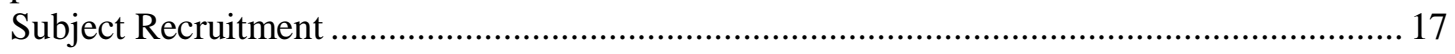

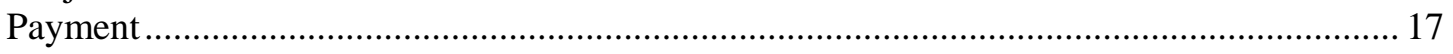

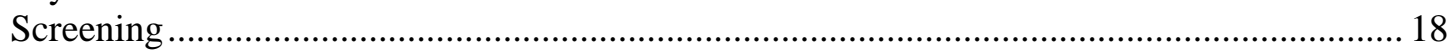

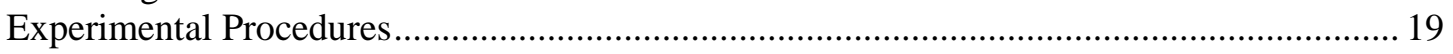

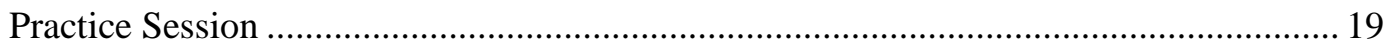

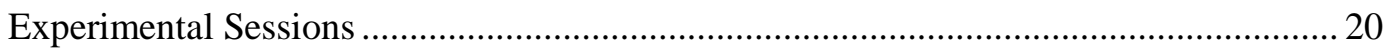

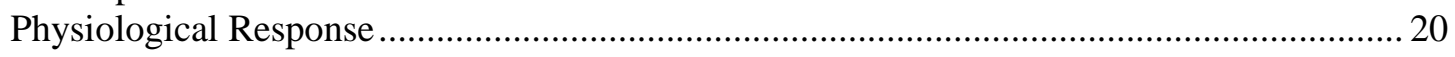

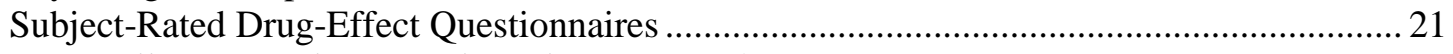

Marijuana Craving Questionnaire (MCQ) Short Form................................................. 21

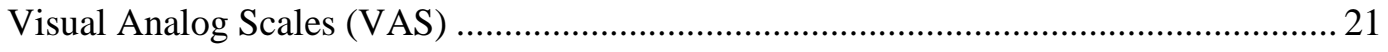

Subject-Rated Physiological Questionnaire ................................................................. 21

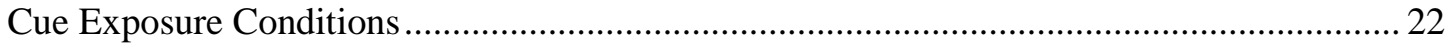

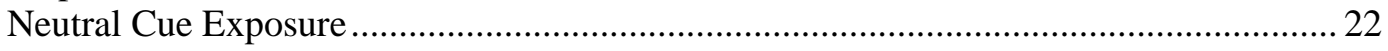

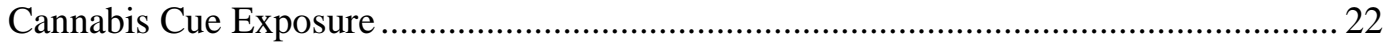

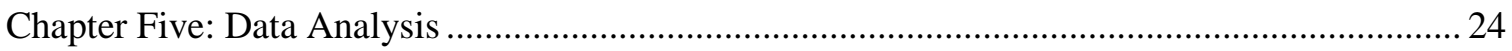

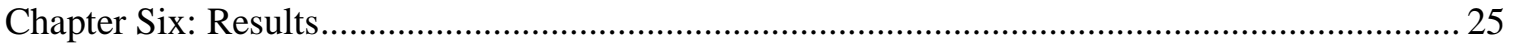

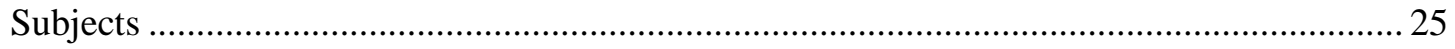




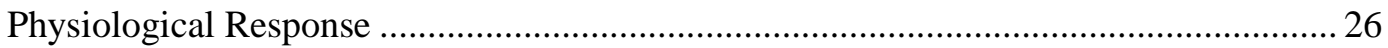

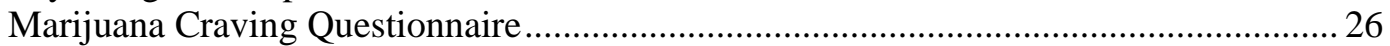

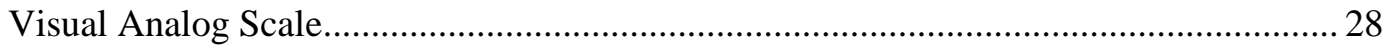

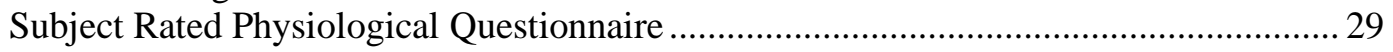

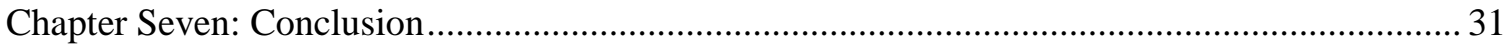

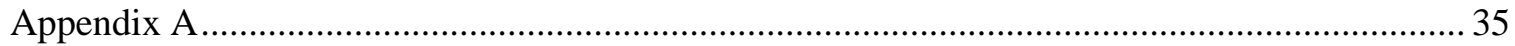

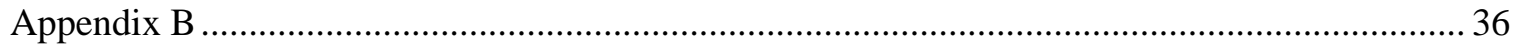

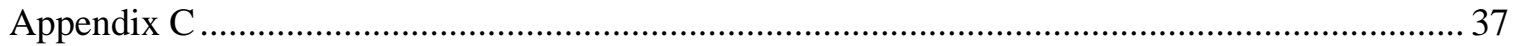

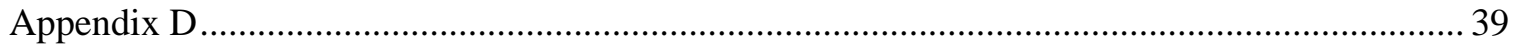

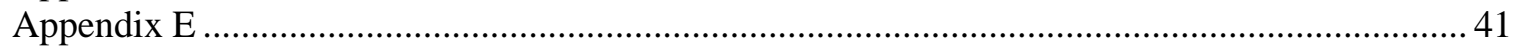

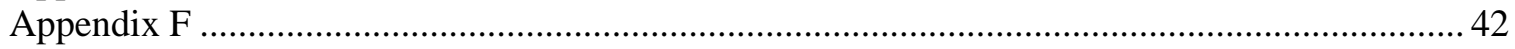

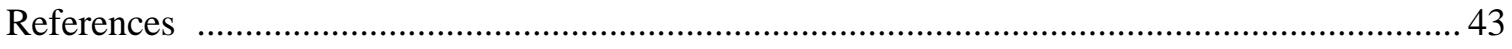

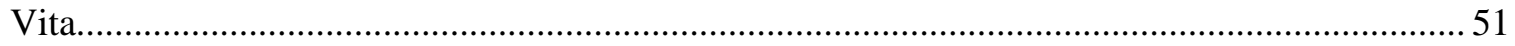




\section{LIST OF TABLES}

Table 4.1. Daily Schedule Timeline

Table 6.1. Subject Demographic Information.

26

Table 6.2. F-values from peak-effect analysis for subject-rated drug-effects measures and physiological indices as compared to the neutral session day 


\section{LIST OF FIGURES}

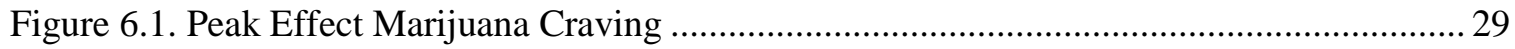

Figure 6.2. Peak Effect Faster Heartbeat..

30 


\section{Chapter One: Significance and Background}

Cannabis (cannabis sativa, cannabis indica) is the most commonly used illicit drug in the United States. Results from the 2013 National Survey on Drug Use and Health (NSDUH) indicated that 6.9 million Americans were dependent on or abusing illicit drugs; cannabis accounted for almost two-thirds (62\%) of that population (4.3 million). Of the 2.8 million people age 12 or older who used illicit drugs for the first time in 2013, $70.3 \%$ reported cannabis as their first illicit drug of abuse. In 2013, lifetime prevalence rates for cannabis use for persons aged 12 or older were 114.7 million (NSDUH, 2013). In 2013, the number of current cannabis users (past 30 days) age 12 or older was 19.8 million, a number that has been increasing every year since 2007 (Substance Abuse and Mental Health Services Administration (SAMHSA), 2013). In 2013, 2.4 million people age 12 or older used cannabis for the first time, an average 6,600 new cannabis initiates every day. 1.4 million (58\%) of the new cannabis initiates began their use prior to the age of 18 (SAMHSA, 2013).

For the vast majority of individuals, cannabis use does not escalate over time and does not interfere with major areas of life functioning. However, approximately $9 \%$ of all cannabis users do in fact become dependent (National Institute on Drug Abuse (NIDA), 2015). That number increases to $17 \%$ among those who start smoking cannabis during their teenage years.

A meta-analysis examining the relationship between cannabis and psychosocial harm found that cannabis use was negatively correlated with educational attainment (Macleod et al., 2004). Similar studies found that adolescent cannabis smokers were less likely to finish high school than their non-smoking peers (Silins et al., 2014). Cannabis use before the age of 25 was also associated with unemployment, lower income, greater welfare dependence, and lower life satisfaction (Ferguson \& Boden, 2008; Brook et al., 2013).

As with other abused drugs, cannabis use significantly impairs motor coordination and reaction time. A number of studies have demonstrated that cannabis intoxication impairs motor vehicle driving similar to alcohol consumption (Groternhermen et al., 2007; Downey et al., 2013). 
The 2011 Drug Abuse Warning Network (DAWN Report) stated that cannabis was a contributing factor in over 455,000 emergency room visits in the United States, an increase of $52 \%$ from 2004. Thirteen percent of those cannabis related emergency department visits were from individuals age 12-17.

\section{Pharmacokinetics}

The cannabis sativa plant contains over 400 different compounds, approximately 60 of which are considered psychoactive. $\Delta^{9}$-tetrahydrocannabinol (THC) is considered the compound that produces the majority of the psychoactive effects associated with cannabis (Gaoni \& Mechoulam, 1964; ElSohly \& Slade, 2005; Ashton, 2001). However, other components of cannabis (e.g. cannabidiol) may also contribute to its psychoactive effects (Borgwardt et al., 2008).

Smoking is the most common route of administration for $\Delta^{9}$-THC is smoking. Cannabis can be hand rolled into cigarettes (joints) or hollowed out cigar papers (blunts), or smoked using glass pipes (bowls) or water pipes (bongs). A typical cannabis cigarette is estimated to contain between 500 and $750 \mathrm{mg}$ of $\Delta^{9}$-THC depending on the potency of the cannabis. This in turn delivers anywhere from 2.5-20 mg of $\Delta^{9}$-THC to the smoker. $\Delta^{9}$-THC absorbed from smoking has a rapid onset and peak blood levels are typically reached within 10 minutes (McLaren et al., 2008; Pol et al., 2014). $\Delta^{9}$-THC blood levels drop to $10 \%$ of the peak level within one hour. However, due to the varying potency among cannabis samples and variability in individual smoking processes, the amount of cannabis that reaches the lungs during each smoking session can vary significantly (Doweiko, 2015).

The medicinal properties of cannabis and its components have been the subject of much research and debate. Currently, there are two FDA approved THC-based medications, dronabinol (Marinol $\left.{ }^{\circledR}\right)$ and nabilone $\left(\right.$ Cesamet $\left.{ }^{\circledR}\right)$. These orally available medications are used for the treatment of nausea in patients undergoing cancer chemotherapy and to stimulate appetite in 
patients with AIDS. Other possible uses of THC-based medications include the treatment of spasticity and neuropathic pain in multiple sclerosis patients, and the treatment of severe childhood epilepsy and seizure disorders (NIDA, 2015).

Cannabis can also be recreationally administered through oral absorption by either mixing cannabis with food or brewed as tea. Oral absorption is typically slower than smoked absorption due to first-pass metabolism (Maykut, 1985). The effects of cannabis are not felt until 30-120 minutes following ingestion. Because a large amount of cannabis is destroyed by the gastrointestinal tract, oral absorption delivers only $4-12 \%$ of available cannabis to the blood (Ashton, 2001).

Once absorbed, $\Delta^{9}$-THC is distributed to the various blood rich organs of the body including the heart and the brain. $\Delta^{9}-\mathrm{THC}$ is then slowly absorbed over time to the less blood rich tissues, such as the body's fat reserves, where it is stored. Chronic daily abuse of $\Delta^{9}$-THC results in large amounts of $\Delta^{9}$-THC being stored in the body's fat cells and users may have $\Delta^{9}$-THC metabolites in their urine for as long as 30 days (Maykut, 1985; McGilveray, 2005).

The primary site of $\Delta^{9}$-THC metabolism is in the liver. The half-life of $\Delta^{9}$-THC depends on the level of tolerance that has developed in the individual user. In chronic daily abusers, the half-life of $\Delta^{9}$-THC can vary anywhere from 24 to 96 hours (Doweiko, 2015). $\Delta^{9}$-THC is almost completely metabolized by hepatic cytochrome P450 enzymes to 11-hydroxy-delta-9-THC (the active metabolite of THC), which is then converted to the inactive metabolite THCCOOH. The inactive metabolite is then excreted in the urine (Huestis, 2007a).

\section{Mechanism of Action and Neurological Correlates}

$\Delta^{9}$-THC imitates the effects of endocannabinoids, naturally occurring ligands in the brain and the periphery. The five known naturally occurring ligands that bind to the endocannabinoid receptors are anandamide, virodhamine, $N$-arachindonoyldopamine, 2-arachidonglycerol, and noladin ether. All of the naturally occurring ligands are derivatives of arachidonic acid and have 
varying degrees of selectivity for the two known cannabinoid receptors, CB-1 and CB-2 (Munro et al., 1993; Pertwee, 1998). Endocannabinoid receptors (CB-1 and CB-2) are metabotropic gprotein coupled. Endocannabinoid receptors are located in large amounts throughout the brain, specifically the cortex, hippocampus, basal ganglia, cerebellum, and spinal cord as well as in the periphery (Julien et al., 2011).

Endocannabinoids are synthesized by a sudden influx of calcium to the cell. After their release from cells, the endocannabinoid transporter protein transports the endocannabinoids into cells where they can be metabolized by fatty acid amide hydrolase (FAAH) (Doweiko, 2015).

CB-1 receptors are located primarily on presynaptic nerve terminals and inhibit calcium influx and facilitate potassium channels resulting in the inhibition of other neurotransmitter release.

$\Delta^{9}$-THC acts as a partial agonist for the CB-1 and CB-2 receptor sites in the brain and the periphery. However, unlike the naturally occurring endocannabinoids, $\Delta^{9}$-THC has a longer halflife, is much more potent, and as a result, is more likely to bind to these receptor sites. There are large numbers of cannabinoid receptors in the brain. However, $\Delta^{9}$-THC only activates approximately $20 \%$ of those receptors. According to receptor reserve theory, since there are such a large number of cannabinoid receptor sites, only a small fraction of these sites need to be occupied in order to elicit a near maximal effect (Pineda, 1997). In the central nervous system, $\Delta^{9}$-THC acts on CB-1 receptors located on presynaptic nerve terminals to inhibit the stimulus evoked release of GABA, NE, and ACh. $\Delta^{9}$-THC reduces the firing rate of these neurons, resulting in the calming, sedating effect (Iverson et al., 2009). Although well documented, the neurobiological mechanism underlying the subjective effects of $\Delta^{9}$-THC is not well understood. However, like other drugs of abuse, $\Delta^{9}$-THC appears to produce its euphoric effects through the brain's endogenous opioid neurotransmitter system (Welch, 2005). 


\section{Pharmacodynamics}

The psychoactive properties of $\Delta^{9}$-THC are subjective and vary based on individual differences and $\Delta^{9}$-THC potency. Acutely, $\Delta^{9}$-THC dose dependently produces behavioral effects including euphoria, analgesia, sensory distortions, relaxation, and decreased anxiety. 50-60\% of cannabis users report experiencing mild anxiety following cannabis administration (Julien et al., 2011). Drug effects typically occur between 10-30 minutes following administration and last anywhere from 2-4 hours.

Physiological effects of $\Delta^{9}$-THC include decreased blood pressure and increased heart rate due to the vasodilation caused by $\Delta^{9}-\mathrm{THC}$ 's actions on CB-1 receptors in blood vessels. Heart rate is typically increased by $30-50 \%$ lasting up to three hours following cannabis use (Sidney, 2002; Doweiko, 2015; Lile et al., 2010a). The vasodilation can also result in reddening of the eyes. Cannabis smokers also experience various respiratory problems such as increased cough, wheezing, acute chest illnesses, and heightened risk of lung infections (Khan et al., 2009).

\section{Consequences of Cannabis Use}

A growing body of research has found significant associations between $\Delta^{9}$-THC and short-term deficits in cognitive functioning. Short-term cognitive effects of $\Delta^{9}$-THC include problems with memory and learning, distorted perception, and difficulty in thinking and problem solving. The negative effects of cannabis on cognitive functioning can last for days or weeks following the discontinuation of heavy use (Doweiko, 2015). Additionally, high-potency cannabis use can result in sensory distortions in some individuals. Chronic cannabis users are at increased risk for experiencing acute psychotic reactions following use. These psychotic reactions tend to dissipate after a few hours or days following use and can include delusions and a loss of the sense of personal identity (Hall, 1998; Johns, 2001; Van Os, 2002).

Previous research determining definitive long-term consequences of cannabis use has been limited. This is mostly due to poly-substance use and variations in medical and physical 
health history among participants (NIDA, 2015). However, in a recent longitudinal study, over 1,000 individuals were followed from birth to 38 years old. At five waves of data collection starting at age 18, cannabis use was assessed. Results from this study found that frequent and persistent adolescent cannabis use was associated with neuropsychological decline, specifically, a decrease of eight points in average IQ score. Furthermore, following cessation of cannabis use in adulthood, participants IQ scores did not improve (Meier et al., 2012). Additionally, a review of 48 studies found that chronic cannabis use has been associated with reduced chances of finishing high school or obtaining a degree (Macleod et al., 2004; Sillins, 2014).

\section{Cannabis Use Disorder}

The fifth edition of the Diagnostic and Statistical Manual of Mental Disorders (DSM-5) has defined Cannabis Use Disorder (CUD) as "a problematic pattern of cannabis use leading to clinically significant impairment or distress" defined by the presence of at least 2 of 11 listed criteria occurring within a 12 month period of time. Some of the DSM-5 criteria for CUD include: craving, failure to fulfill major role obligations, tolerance, and withdrawal.

DSM-5 was the first edition to recognize cannabis withdrawal as diagnostic criteria. Common withdrawal symptoms include irritability, anxiety, sleep difficulty, restlessness, and depressed mood. Withdrawal symptoms occur in over $50 \%$ of users who discontinue cannabis use. Withdrawal symptoms usually begin within 48 hours of cessation of use and can last anywhere from 2-19 days (Julien et al., 2011). Despite the noted withdrawal reactions, withdrawal symptoms experienced with cannabis are far less intense than those experienced with other drugs of abuse such as alcohol, benzodiazepines, or opiates. However, withdrawal has been associated with repeated cannabis use and users report withdrawal symptoms as a trigger for relapse during quit attempts (Haney et al., 2013a; 2004; Cornelius et al., 2008).

\section{Current Treatment Modalities}

Prior to 1994, there were no published controlled research studies focusing on the treatment of cannabis abuse or dependence (Steinberg et al., 2005). This may be due to previous 
misconceptions that cannabis use did not lead to dependence and that there were no adverse effects associated with cannabis misuse. We now know that roughly $10 \%$ of people who use cannabis become daily users (McRae et al., 2003). Coffey and colleagues (2002) found that people who smoke cannabis more than once a week were at a significant risk for dependence. In the 1990s, the number of people who sought treatment for cannabis dependence more than doubled. As a result, there was a significant increase in the development of treatment interventions focusing on cannabis dependence, including both behavioral interventions and pharmacotherapies.

Behavioral Interventions. Overall, behavioral interventions such as motivational enhancement therapy (MET) (Copeland et al., 2001), cognitive-behavioral therapy (CBT) (Stephens et al., 1994), contingency management (CM) (Budney et al., 2000; 2006), and familybased treatments, have reduced cannabis use and increased abstinence relative to delayedtreatment control conditions. The Marijuana Treatment Project (MTP), a large multi-site study, examined the efficacy of treatment outcomes from three different behavioral interventions with 450 ethnically diverse cannabis dependent adults. Results from the MTP suggest that both a twosession MET treatment and a nine-session treatment incorporating MET, coping skills training, and case management were significantly more effective in reducing cannabis use than a delayedtreatment control condition. Additionally, cannabis dependence and anxiety symptoms were reduced following both the two- and nine-session treatment interventions, with the nine-session intervention showing the greatest improvement (Steinberg et al., 2005). Unfortunately, long-term success rates of behavioral interventions of CUDs are limited. Across several behavioral intervention studies, only 10-30\% of individuals remain abstinent after one year (Budney et al., 2007a). Because behavioral therapies have shown limited success, there is a recognized need for research on the development of pharmacotherapies to assist treatment seekers with the initiation and maintenance of abstinence. 
Pharmacotherapies. Currently, there are no FDA approved medications for the treatment of cannabis dependence or for the management of cannabis withdrawal or craving. Research studies and subsequent pharmacotherapies have been developed for the treatment of alcohol, nicotine, and opioid dependence. However, until recently, research efforts focusing on pharmacotherapies for cannabis use disorders have been minimal by comparison. Laboratory studies have been designed to examine the efficacy of several medications in the attenuation of cannabis withdrawal symptoms, subjective and reinforcing effects, and to prevent relapse.

Dronabinol. Dronabinol is chemically synthesized $\Delta^{9}-$ THC and acts as a partial agonist. Dronabinol is available under the trade name Marinol ${ }^{\circledR}$ in $2.5,5$, or $10 \mathrm{mg}$ capsules for oral administration. Marinol ${ }^{\circledR}$ is used for stimulating appetite and preventing weight loss in patients with AIDS and treating nausea and vomiting caused by cancer chemotherapy. For these reasons, dronabinol has been used in laboratory settings as a potential medication adjunct for cannabis relapse and withdrawal.

Laboratory studies have shown that varying doses of dronabinol (10, 20, and $30 \mathrm{mg}$ ) administered multiple times daily attenuate withdrawal symptoms typically associated with CUDs (Haney et al., 2004; 2008; Budney et al., 2007b). In a similar study by Vandrey and colleagues (2013), daily cannabis smokers were given oral doses of dronabinol (0, 30, 60, and $120 \mathrm{mg})$ for five days. On the fifth day of dronabinol maintenance, subjects smoked five puffs of a cannabis cigarette. Results showed that dronabinol dose-dependently decreased cannabis withdrawal. Similar results were demonstrated by Levin and colleagues (2011). In this 12-week randomized placebo-controlled trial, 156 cannabis dependent adults were administered $20 \mathrm{mg}$ twice daily of dronabinol or placebo. Results showed that dronabinol significantly improved treatment retention and withdrawal symptoms relative to placebo. However, dronabinol did not significantly effect post-treatment cannabis use or abstinence rates.

Dronabinol has also been shown to attenuate the subjective effects of smoked cannabis. In one such study by Hart and colleagues, (2002) healthy cannabis dependent individuals were 
given oral doses of dronabinol (either 0,10 , or $20 \mathrm{mg}$ ) for three days followed by three days of placebo maintenance. Relative to placebo, dronabinol maintenance significantly decreased subjective reporting of "Good Drug Effect" and "High" following smoked cannabis administration (1.8\% $\Delta^{9}$-THC). Other studies however, have failed to demonstrate a reduction in subject effects of smoked cannabis following dronabinol administration (Vandrey, 2013).

Nabilone. Nabilone is a synthetic analog of THC that acts as a CB-1 agonist. Nabilone is currently used for the control of nausea and vomiting caused by chemotherapy. Drug discrimination studies show that nabilone substituted for dronabinol (Lile et al., 2010b). For these reasons, nabilone has been used in laboratory settings as a potential medication adjunct for cannabis relapse and withdrawal. In one such study by Haney and colleagues (2013b), healthy cannabis dependent individuals were given oral doses of nabilone $(0,6$, and $8 \mathrm{mg} /$ day $)$ under both placebo and active cannabis self-administration conditions. Both active nabilone conditions attenuated cannabis self-administration and decreased withdrawal symptoms.

Naltrexone. Naltrexone acts as an opioid antagonist at all three opioid receptors, with the highest affinity for the $\mu$ opioid receptor. Preclinical research has demonstrated that naltrexone blocks the effects of cannabis (see Weinstein \& Gorelick, 2011 for review). In cannabis users, results of naltrexone use have been mixed. Previous human studies have demonstrated that acute pretreatment of naltrexone actually increased the positive subjective effects of cannabis (Cooper \& Haney, 2010). Other studies have shown that naltrexone maintenance decreases cannabis selfadministration and subjective VAS ratings of "Good Effect” (Haney et al., 2015).

Rimonabant. Rimonabant acts as a selective, potent, and orally active CB-1 receptor antagonist. Rimonabant was developed as a CB-1 antagonist and proved successful at blocking the effects of $\Delta^{9}$-THC in pre-clinical studies (Tseng \& Craft, 2004). Rimonabant has been approved for use in Europe and other countries; however it has not been approved in the United States. Acute administration of rimonabant has been shown to reduce subjective drug effects in 
cannabis dependent individuals (Huestis et al., 2001). In a double-blind, randomized trial, subjects received either 0,40 , or $90 \mathrm{mg}$ of rimonabant. During two laboratory sessions, subjects smoked either active or placebo cannabis. Both active rimonabant conditions attenuated the acute physiological effects of smoked cannabis and acutely attenuated subjective responses (Huestis et al., 2007b).

Nabiximols. Nabiximols is a cannabinoid receptor agonist and the first cannabis-based medication licensed in the UK. It is currently approved for muscle spasticity related to multiple sclerosis. Nabiximols is an oromucosal spray containing $\Delta^{9}$-THC and cannabidiol. Because of its route of administration, nabiximols has a more predictable pharmacokinetic profile than oral THC and has a lower abuse potential than dronabinol (Schoedel et al. 2011). In a double-blind, randomized, placebo-controlled clinical inpatient trial, subjects were given either active nabiximols (maximum daily dose, $86.4 \mathrm{mg}$ of $\Delta 9$-tetrahydrocannabinol and $80 \mathrm{mg}$ of cannabidiol) or placebo. Acutely, nabiximols significantly reduced cannabis withdrawal relative to placebo. Additionally, nabiximols improved patient retention in treatment (Allsop et al., 2014).

Other possible pharmacotherapy agents investigated have included buspirone, lithium, lofexidine, N-acetyl cycteine (NAC), and gabapentin (see Vandrey \& Haney, 2009 for review; see Balter et al., 2014 for review). NAC and gabapentin in particular, have been tested in randomized control trials. In an 8-week double-blind randomized placebo-controlled trial, 116 cannabis-dependent adolescents received either $1200 \mathrm{mg}$ of NAC or placebo. Results showed that adolescents in the NAC treatment condition had more than twice the odds relative to placebo of having a THC negative urine toxicology screen during treatment (Gray et al., 2012). In a 12week double-blind randomized placebo-controlled trial, cannabis-dependent adults received either $1200 \mathrm{mg}$ of gabapentin or placebo. Results showed that gabapentin significantly reduced cannabis use and cannabis related withdrawal symptoms relative to placebo (Mason et al., 2012).

There is a need for increased research on the development of more effective pharmacotherapies for CUDs. Although numerous possible pharmacotherapy agents have been 
studied, none have been approved by the FDA for the treatment of CUDs. Research has shown that a combination of pharmacotherapy and behavioral interventions result in greater treatment improvement outcomes relative to either intervention alone (Vandrey \& Haney 2009).

\section{Craving and Cue Exposure}

It is generally understood that an interaction between various biological, psychological, and social factors contribute to addiction and relapse. One of the primary goals of drug treatment programs is for the individual to achieve and maintain abstinence from drug use. Drug craving is an intense, emotional, and physical experience resulting in an impulse to use drugs. Drug craving can interfere with an individual's ability to maintain abstinence after quit attempts. Craving can elicit physiological responses similar to those associated with substance abuse including anxiety, increased heart rate, and sweaty palms. Craving for cannabis is a key element of the withdrawal syndrome that has been characterized in abstinent individuals with a history of chronic use. Craving has been associated with continued substance use and relapse during quit attempts in the natural environment, but not causally linked in a laboratory setting (Drummond et al., 2000; Weiss, 2005; Carter \& Tiffany, 1999; Childress et al., 1993).

Exposure to drug cues (e.g., handling drug paraphernalia, audio and visual drug-related stimuli) induces robust subjective reports of craving. Cue-induced craving for cocaine (Robbins et al., 1992), opioids (Hyman et al., 2007), alcohol (Fox et al., 2007), and tobacco (Ferguson \& Shiffman, 2009) has been established in laboratory settings. Previous research has also demonstrated increased subjective craving responses in cannabis dependent individuals following exposure to cannabis cues.

In one such study, daily cannabis users and a control group of cannabis-naïve individuals were exposed to both neutral cues and cannabis cues in a single laboratory session. During the neutral phase, subjects were exposed to a variety of neutral objects (i.e., pencils, eraser, ruler). Subjects were instructed to handle and smell the objects while viewing a videotape of nature scenes. After a brief rest period, the cannabis phase began. During this phase, subjects were 
exposed to a variety of cannabis-related paraphernalia (i.e., bong, pipe, papers). Subjects were instructed to handle and smell the objects while viewing a videotape of young adults smoking. Mood and subjective craving effects were measured at baseline and following both the neutral and cannabis phases. Responses on the craving measures increased from baseline following cannabis cues relative to neutral cues, but only for the cannabis dependent group (Lundahl \& Johanson, 2011). Similar single session studies examining cue reactivity in cannabis smokers also found greater subjective craving responses during the presentation of cannabis cues relative to neutral cues (Nickerson et al., 2011, Gray et al., 2008; 2011; Bordnick et al., 2009; McRae-Clark et al., 2011). Skin conductance also increased during the presentation of cannabis cues relative to neutral cues (Gray et al., 2008; 2011; Wolfling et al., 2008).

Successful use of a cue-induced craving within-subjects design has been demonstrated in a recent study by Lundhal and Greenwald (2015). In this study, 14 cannabis dependent individuals were pretreated with placebo, 10, or $20 \mathrm{mg}$ of oral THC. Following THC administration, subjects were exposed to a 10 minute neutral cue exposure followed by a 10 minute cannabis cue exposure. Results showed significant increases on the Marijuana Craving Questionnaire (MCQ) compulsivity scores following cannabis cues relative to neutral cues. Additionally, significant increases were found on Visual Analog Scale (VAS) items "desire to use marijuana," "urge to smoke marijuana," and "craving for marijuana."

\section{Behavioral Models of Drug Use and Craving}

Behavioral models of substance abuse are primarily influenced by B. F. Skinner's operant learning theory and Ivan Pavlov's classical conditioning theory. Operant conditioning models are based on the notion that drug use and addiction are maintained through general learning and reinforcement principles. According to this model, drug-taking behaviors are initiated and maintained because of the positive reinforcing effects of drug use. Following cessation of drug use, individuals are likely to experience increased discomfort associated with craving and 
withdrawal. According to the operant learning model, relapse to drug use can be understood as a means of reducing the negative discomfort associated with craving and withdrawal.

Ivan Pavlov's classical conditioning model is useful in understanding the processes involved in cue-induced craving. In its most basic form, a neutral stimulus (NS) is paired with an unconditioned stimulus (US) that innately elicits a central nervous system physiological response (UR). When administered alone, the NS does not elicit the physiological response. However, through repeated pairings of the NS and US, the NS becomes a conditioned stimulus (CS) eliciting a conditioned response (CR) (Seigel \& Ramos, 2002). Through the process of classical conditioning, stimuli that have been previously associated with drug taking behavior (e.g., drug paraphernalia) act as conditioned stimuli in absence of the actual drug of abuse. The classical conditioning model demonstrates how through repeated pairings, drug cues serve as discriminative stimuli (paraphernalia, environment, viewing drug use, etc.) and elicit neurobiological changes resulting in drug craving symptoms (see Carter \& Tiffany, 1999 for review).

Cannabis dependence is a chronically relapsing condition (Koob, 2006; Taylor et al., 2009). Craving is a key element in relapse and can occur following periods of abstinence. In cue exposure treatment models, a client is presented with drug cues; however, the client is prevented from taking drugs. The theory is that this extinction procedure, overtime, can lead to breaking the classical conditioning pairing resulting in decreases in reactivity to drug cues. Results, however, have been mixed. Preclinical research has demonstrated that cue exposure models can be used to attenuate drug-seeking behavior (Buffalari et al., 2013; Kearns et al., 2012). However, other preclinical studies have not shown reduction in drug-seeking behavior (Crombag et al., 2002). Similarly, in humans, the results of cue exposure therapy (CET) are mixed. Some CET studies show promise as an adjunct treatment (Lee et al., 2007; Santa Ana et al., 2015), while others actually show increased relapse rates compared to placebo (Marissen et al., 2006). 


\section{Craving as a Construct}

Although previous literature highlighted the importance of cue-induced craving, the specific construct of craving and its validity as a laboratory measure have been widely debated. One of the major problems when exploring craving as a construct is variation in methodology used. Drug craving can be measured through self-report questionnaires, physiological indices (i.e., blood pressure, heart rate), or behavioral paradigms (i.e., self-administration). As a result, standard methods of measuring subjective craving in laboratory settings have yet to be established (Marlatt 1990, Tiffany et al., 2000). Another issue arises when discussing the variations in self-reported craving. Specifically, researchers differ as to whether craving should be assessed across a broad continuum (i.e., Visual Analog Scale) or with a more limited characterization (i.e., Marijuana Craving Questionnaire). As a result, construct validity has been almost impossible to establish (Sayette, 2000).

The operational definitions notwithstanding, exposure to drug cues have been shown to increase subjective reports of craving across all drugs of abuse in laboratory settings. There is a need for a better understanding of the factors that contribute to continued drug use despite quit attempts in order to develop models and procedures for the evaluation of behavioral and pharmacological therapies for treatment. The disproportionate amount of CUDs and new initiates relative to treatment seekers highlights the importance of developing new treatment modalities for cannabis use disorders.

Copyright $@$ Jessica S. Fogel 2015 


\section{Chapter Two: Purpose of Project}

The purpose of the present protocol was to test whether a cue reactivity procedure could elicit a craving response within-subjects in a laboratory setting and to see whether those craving responses could be sustained across multiple sessions. In general, previous cue reactivity paradigms have used group designs and have not reported on the test-retest reliability of the craving response to drug cues. Considering the strength of within-subjects designs in medication development research, an important step would be to demonstrate that cue-induced craving responses of similar magnitude can be elicited in the same subjects across multiple sessions.

Craving can be an important contributor to relapse following quit attempts. Subjective drug craving is an important component of the addiction process that is not captured through other studied laboratory models of addiction such as pharmacological selectivity (Lile et al, 2011; 2012), self-administration (Haney et al., 1997), or attentional bias (Field \& Cox, 2008). A better understanding of the craving processes is important in helping individuals maintain sobriety following quit attempts.

The present study focused on the effects of cue exposure on subjective craving. Drug cravings are intense subjective experiences that can be triggered by internal stimuli or external

drug cues. Because of the subjective nature of craving responses, the present study examined individual subjective responses to cue-induced craving.

Copyright (C) Jessica S. Fogel 2015 


\section{Chapter Three: Hypothesis}

\section{Behavioral}

Exposure to cannabis cues will produce more robust craving responses than exposure to neutral cues. Following neutral cue presentation, daily cannabis smokers will report no change on the subject-rated craving responses from baseline. Changes on other VAS items will not be affected. Following cannabis cue presentation, daily cannabis smokers will report an increase on subject-rated craving responses from baseline. It was also hypothesized that subject rated craving responses to cannabis cues would be sustained across multiple cue exposure sessions.

\section{Physiological}

Consistent with previous studies, no changes from baseline are anticipated following the neutral and cannabis cue presentations on either the subject rated physiological questionnaires or cardiovascular physiological measures.

Copyright (C Jessica S. Fogel 2015 


\section{Chapter 4: Method}

The proposed experiment and informed consent document have been approved by the Institutional Review Board of the University of Kentucky Medical Center.

\section{Subject Recruitment}

Subjects were recruited through local community internet, newspaper and radio advertisements, bulletin board postings, and word-of-mouth. Inclusion in the study was contingent on daily cannabis use. Subjects needed to be between the ages of 18-50 and in good health except for their drug use. Tactile, auditory, or visual conditions that would impact perception of drug cues, history of serious physical or psychiatric disease, and current use of psychiatric medications were exclusionary. Additionally, subjects who wished to seek treatment for their drug use were also excluded from the study. During the recruitment phase, subjects were not informed of the specific inclusion/exclusion criteria noted above.

Subjects made initial contact with the research facility either by phone or through the internet (http://rrf.research.uky.edu/). During this initial contact, a brief screening regarding the inclusion/exclusion criteria was conducted. Prospective subjects were then provided with additional details of the study and were invited to begin the screening component. All potential subjects who were identified using the recruitment methods noted above received oral and written descriptions of the study prior to providing written consent.

\section{Payment}

Subjects were paid \$20 for completing the screening packet. Subjects were paid \$20 for a practice session and $\$ 20$ for each of the five subsequent experimental sessions. Subjects received an additional \$20 completion allowance for each of the six sessions ( 1 practice +5 experimental) if they completed the entire experiment. Subjects who were terminated for medical reasons received all of the money they earned through their termination date as well as the $\$ 20$ 
completion allowance. The maximum amount of money a subject could receive was $\$ 260(\$ 240$ for study participation $+\$ 20$ for screening).

\section{Screening}

Initial in-person screenings lasted between one and three hours and were conducted at the UK Residential Research Facility (RRF). During the initial screening, subjects were given the IRB-approved informed consent document to read and sign. Subjects were advised of the voluntary nature of participation and of their right to withdraw from the project at any time. Subjects were also advised of aspects of the study protocol including potential study risks and benefits, payment, confidentiality of information, and rights as a research participant. Subjects were required to abstain from cannabis use on the day of, and from alcohol use 12 hours prior to the experimental session. Repeated alcohol and drug violations resulted in dismissal from study participation. Study investigators addressed any questions or concerns the subject had prior to obtaining consent. Subjects were informed that staff members were available at any point during the study to answer questions or explain study procedures.

Once the subject agreed to participate in the present protocol, a breathalyzer and urine toxicology screen was conducted. Breath samples positive for alcohol or a urine sample positive for drugs of abuse (other than cannabis) precluded the subject from participation in screening that day. Subjects were also asked to provide an expired air sample that was tested for the presence of carbon monoxide $(\mathrm{CO})$.

Subjects then completed computerized screening assessments which included information about: demographics, family medical history, past and present medical and mental health history, past and present drug and cannabis use history, and the Structured Clinical Interview for DSM-IV (SCID). Subjects then filled out a Cannabis Use Calendar (Appendix A). This was followed by an assessment of vital statistics including heart rate, blood pressure, and weight. Subjects were paid for their participation in the initial screening. 
Of note, screening procedures for behavioral pharmacology studies conducted at the RRF typically include a physical health screening (blood/urine analysis and ECG) with results reviewed by a study physician. However, because of the minimal risk associated with the protocol and because drugs were not administered, these procedures were not included.

\section{Experimental Procedures}

Experimental procedures were conducted on an outpatient basis at the RRF. Upon arrival, subjects relinquished their keys, watches, and mobile phones, which were stored securely until the end of the session. A field sobriety test was then conducted to ensure that subjects were not intoxicated prior to session initiation. A breathalyzer and urine toxicology screen were conducted. Breath samples positive for alcohol or a urine sample positive for drugs of abuse (other than cannabis) precluded the subject from participation in the experimental session. Urine samples from female subjects that were positive for pregnancy resulted in dismissal from the study.

Subjects then completed the Sign-In Questionnaire that assessed past 24-hour nicotine, alcohol, caffeine, and cannabis use, medication use since their last session, and any changes in their normal routine. The Sign-In Questionnaire can be found in Appendix B. Subjects who smoked cigarettes were then allowed to smoke a single cigarette before the session began. Subjects were not allowed to smoke again until the end of the experimental session.

The study consisted of one practice and five experimental ( 1 neutral +4 cannabis cue) sessions. Experimental session rooms at the RRF were equipped with Macintosh computers programmed to present the sessions tasks in a prearranged sequence. Data were stored in files coded for participant identity protection. Files were backed up at the end of each session.

Practice session. Subjects completed a practice session prior to beginning experimental sessions to familiarize them with the behavioral tasks and timeline of the experimental protocol described below. During these practice sessions, subjects were exposed to the neutral, but not cannabis, cue condition. 
Experimental sessions. Subjects completed five experimental sessions after successfully completing the practice session. Experimental sessions included behavioral tasks as well as either a cannabis or neutral cue presentation. The order of cue presentations was randomly assigned.

The timeline for the experimental sessions is shown in Table 4.1 below. The complete Study Run Sheet is shown in Appendix C.

Table 4.1. Daily Schedule Timeline

\begin{tabular}{|l|l|}
\hline Time & $\begin{array}{l}\text { Procedure } \\
-30\end{array}$ \\
& $\begin{array}{l}\text { Check in Procedures (BAC, CO, urine toxicology, weight, Sign-In } \\
\text { Questionnaire) }\end{array}$ \\
\hline 0 & MCQ, VAS, HR, BP \\
\hline 5 & Cue Exposure, Physiological Questionnaire, MCQ, VAS, HR, BP \\
\hline 30 & MCQ, VAS, HR, BP \\
\hline 60 & MCQ, VAS, HR, BP \\
\hline & Check out Procedures \\
\hline
\end{tabular}

Physiological measures assessed during the four noted time points included heart rate and blood pressure. Subjective responses were assessed during the four noted time points with the Marijuana Craving Questionnaire (MCQ) Short Form and the Visual Analog Scale (VAS). Immediately following the cue presentation, subjects filled out an 11-item Subject-Rated Physiological Questionnaire that was locally developed.

\section{Physiological Response}

Heart rate and blood pressure were measured using a Dinamap digital monitor (Critikon, Pro 200, Tampa, FL). Vital signs were measured during the practice and experimental sessions at baseline, immediately following the cue presentation, 30 minutes following baseline, and 60 minutes following baseline. 


\section{Subject-Rated Drug-Effect Questionnaires}

Marijuana Craving Questionnaire (MCQ) Short Form. The Marijuana Craving

Questionnaire (MCQ) was developed and validated as a 47-item self-report assessment

(Heishman et al., 2001). In 2009, a short form of the questionnaire was developed as a 12-item

assessment divided into four subscales: compulsivity, emotionality, expectancy, and

purposefulness. There are three MCQ items in each of the four subscales. Subjects were shown

statements regarding cannabis use and anticipated effects on a computer screen and were asked to

indicate their answer by using a computer mouse to select one of 7 options ranging from

“strongly disagree" (scored as 1) to "strongly agree" (scored as 7). Composite scores are

produced for each subscale, with a maximum score of 21 on each subscale. The MCQ short form is reprinted in Appendix D.

Visual Analog Scales (VAS). Subjects were asked to rate themselves across nine different dimensions (e.g. shaky or jittery, restless) and five self-report craving items by placing a mark on a 100-unit line with the left endpoint of the continuum labeled "Not at all" and the right endpoint labeled "Extremely." Each item was scored by how many millimeters the participant placed the marker from the left end of the scale indicating "Not at all" (scored as 0 ) to the right end of the scale indicating "Extremely" (scored as 100). The maximum possible score for any of the VAS items was 100. Due to a possible ceiling effect (i.e., craving levels are elevated and therefore insensitive to the experimental manipulation), subjects who scored greater than or equal to 50 out of 100 on the VAS "Cannabis craving" item during the neutral session were not included in the present analysis. VAS items are found in Appendix E.

Subject-Rated Physiological Questionnaire. The Subject-Rated Physiological Questionnaire was administered one time only immediately following the cue exposure. Subjects were asked to rate how strongly they experienced 11 different physiological symptoms (e.g. faster heart rate, rapid breathing). Subjects were asked rate how they were thinking or feeling during the time they were handling the objects during the cue exposure. Items were rated on a five-point 
scale ranging from "Not at all" (scored as 0) to "All of the time" (scored as 4). The Subject-Rated Physiological Questionnaire is reprinted in Appendix F.

\section{Cue Exposure Conditions}

Cue exposure conditions lasted eight minutes and included a three-minute tactile cue, a one-minute imagery prompt, and a four-minute visual cue. For the tactile cue, an opaque pitcher containing either neutral or cannabis physical cues was placed on the participant's desk at the beginning of each of the cue exposure sessions. Following each cue presentation, subjects completed the Subject-Rated Physiological Questionnaire, MCQ, and VAS. In addition, heart rate and blood pressure were taken.

Neutral cue exposure. Neutral cue exposure instructions were displayed on the computer screen. The neutral cue exposure timeline was as follows:

\section{Time (seconds)}

0

60

\section{Instructions}

Please remove the cover and look at the objects.

Please pick up and hold the objects.

Please place the objects back on the tray and replace the cover.

Please think of a recent time and place where you were most relaxed.

Video starts: (run time: 4 minutes)

Video ends: Subject-Rated Physiological Questionnaire, MCQ, VAS, HR, BP

Objects presented during the neutral cue exposure included a variety of school supplies (e.g. pencils, erasers, a ruler). The video presented during the neutral cue was of various nature scenes (e.g. waterfalls, mountains). At the conclusion of the video the assessments began.

Cannabis cue exposure. Cannabis cue exposure instructions were displayed on the computer screen. The cannabis cue exposure timeline was as follows: 
Time (seconds)

0

60

180

\section{Instructions}

Please remove the cover and look at the objects.

Please pick up and hold the objects.

Please place the objects back on the tray and replace the cover.

Please think of a recent time and place when you enjoyed smoking cannabis.

Video starts: (run time: 4 minutes)

Video ends: Subject-Rated Physiological Questionnaire, MCQ, VAS, HR, BP

Objects presented during the cannabis cue exposure were a variety of cannabis paraphernalia (e.g., a rolled joint containing an inactive cannabis substitute, pipe, rolling papers). The video presented during the cannabis cue exposure was of young adults smoking (e.g., preparing to smoke, smoking in several different settings). At the conclusion of the video the assessments began.

Copyright (C) Jessica S. Fogel 2015 


\section{Chapter Five: Data Analysis}

Statistical analyses were used to investigate the effects of cue exposure on subjective and physiological assessments. For all statistical analyses, effects with $\mathrm{p} \leq .05$ were considered significant. Daily peak effects following cue exposure were analyzed using one-factor, repeatedmeasures ANOVA with cue exposure session (cannabis 1, cannabis 2, cannabis 3, cannabis 4, and neutral) as factors. If a main effect of session type attained statistical significance, planned comparisons of active drug cue exposure session days to the neutral cue exposure session were conducted.

Copyright @ Jessica S. Fogel 2015 


\section{Chapter Six: Results}

\section{Subjects}

Eleven $(5 \mathrm{M}, 6 \mathrm{~F})$ non-treatment-seeking daily cannabis users were included in the present analysis. Ages ranged from 19 to 29 years. Seven of the subjects were White; four of the subjects were Black. Subjects had been smoking cannabis for an average of six years with a range of 2 years to 13 years of use. Table 6.1 presents the age, weight, race, self-reported daily caffeine and

cigarette use, weekly alcohol and cannabis use, and number of years using cannabis for the eleven subjects.

Twenty-two subjects reported to the RRF for the initial screening procedures. Of the 22, four were excluded because they did not meet the cannabis use criteria (smoked less than 25 days per month), two were excluded because of repeated drug and alcohol abstinence violations, one was excluded because of a positive PTSD SCID diagnosis, and one voluntarily discontinued her involvement in the study. Of the 14 remaining subjects, three were excluded because of high baseline levels of VAS cannabis craving scores. Subject demographic information is presented in Table 6.1. 
Table 6.1. Subject demographic information.

\begin{tabular}{|l|c|}
\hline Sex & N = 5 M, 6 F \\
\hline Race/Ethnicity & N = 7 White, 4 Black \\
\hline & $21.13(3.52)$ \\
\hline Age & $154.65(25.41)$ \\
\hline Weight (lbs) & $27(1.68)$ \\
\hline Marijuana (days/month) & $6(3.79)$ \\
\hline Number of years used marijuana & $1.67(1.31)$ \\
\hline Alcohol (days/week) & $2.1(3.38)$ \\
\hline Cigarettes (per day) & $140.8(83.83)$ \\
\hline Caffeine (mg/day) & \\
\hline
\end{tabular}

Physiological response. No significant differences were found on physiological measures (i.e., BP and heart rate) following cannabis cue conditions relative to the neutral cue condition. F-values are shown in Table 6.2.

Marijuana Craving Questionnaire. No significant cue exposure effects were found for any of the MCQ composite scores. F-values are shown in Table 6.2. 
Table 6.2. F-values from peak-effect analysis for subject-rated drug-effects measures and physiological indices as compared to the neutral session day (Bold indicates a significant F-

value).

\section{Outcome Measures}

Physiological Response

Heart Rate

Blood Pressure

Diastolic

Systolic

Subject-Rated Drug Effect Questionnaires

Marijuana Craving Questionnaire (MCQ)

Composite Scores

Compulsivity

Emotionality

Expectancy

Purposefulness

Visual Analog Scale (VAS)

IFeel...

Sedated

Stimulated

Nauseated

Shaky or Jittery

Restless

Dizzy

Difficulty Concentrating

Anxious

Nervous

I Have a Craving For...

Alcohol

Tobacco

Marijuana

Cocaine

Opiates
F-Values

$2.33(\mathrm{p}=0.07)$

$2.44(\mathrm{p}=0.06)$

0.95

0.57

2.08

0.17

1.28

1.49

1.23

0.76

0.89

0.92

1.00

0.74

1.19

0.54

0.68

2.30

$2.92(\mathrm{p}<0.05)$ 
Table 6.2 (continued). F-values from peak-effect analysis for subject-rated drug-effects measures and physiological indices as compared to the neutral session day (Bold indicates a significant F-value).

Subject-Rated Physiological Questionnaire

Faster heart rate

Rapid breathing

$4.04(\mathrm{p}<0.01)$

Sweating hands

1.00

Heavy feeling in stomach

1.00

Loud pounding heart

$--$

Tensed muscles

0.73

Cold hands

0.43

Feeling flushed or hot

1.35

Salivating more

1.00

Trembling

1.97

Dry mouth

Visual Analog Scale. A one-factor, repeated-measures ANOVA revealed a significant effect of cue exposure condition on subjective craving response on the VAS item "I have a craving for Marijuana" $\left(\mathrm{F}_{4,40}=2.92, \mathrm{p}<0.05\right)$. Contrasts indicated that the mean score for subjects in the initial cannabis cue condition $(M=20.09, S D=20.26)$ was significantly higher than the mean score for subjects in the neutral cue condition $(M=9.18, S D=11.46)$. Results showed subjects experienced greater subjective cannabis craving responses following the Day 1 cannabis cue exposure compared to neutral cue exposure. No significant differences were found on subsequent cannabis cue conditions (i.e., day 2-4) relative to the neutral cue condition. Results are shown in Figure 6.1. F-values are shown in Table 6.2. 
Figure 6.1.

\section{Peak Effect Marijuana Craving}

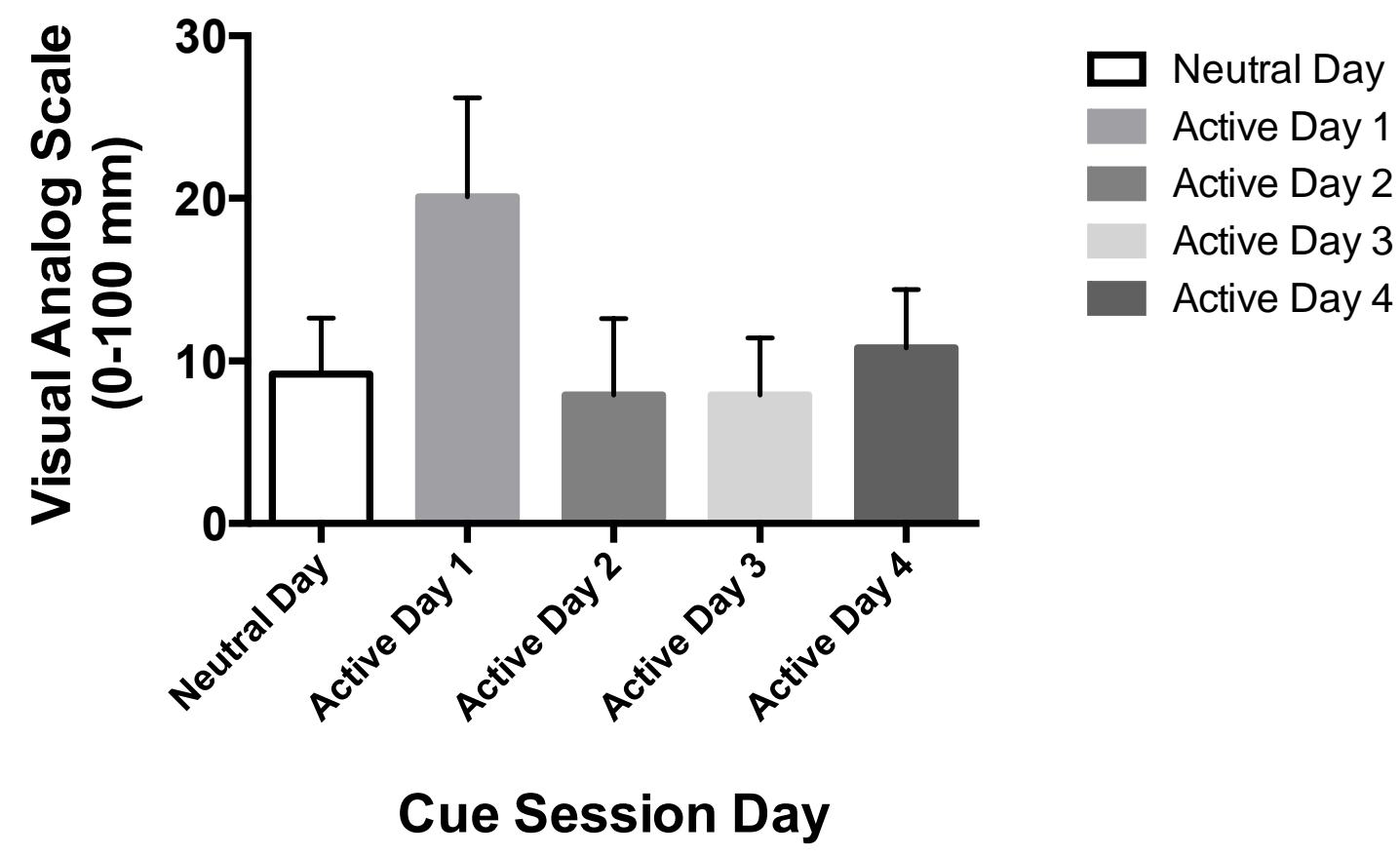

Subject-Rated Physiological Questionnaire. A one-factor, repeated-measures ANOVA revealed a significant effect of cue exposure condition on subject-rated physiological response during the tactile cue presentation. Specifically, subjects reported significant increases in subjective awareness of a faster heart rate $\left(\mathrm{F}_{4,40}=4.04, \mathrm{p}<0.01\right)$ following the initial cannabis cue condition $(\mathrm{M}=1.45, \mathrm{SD}=0.52)$ as compared to the neutral cue condition $(\mathrm{M}=1.00, \mathrm{SD}=$ 1.00). No significant differences were found on the Subject-Rated Physiological Questionnaire responses on subsequent cannabis cue conditions (i.e., day 2-4) relative to the neutral cue condition. Results are shown in Figure 6.2. F-values are shown in Table 6.2. 
Figure 6.2.

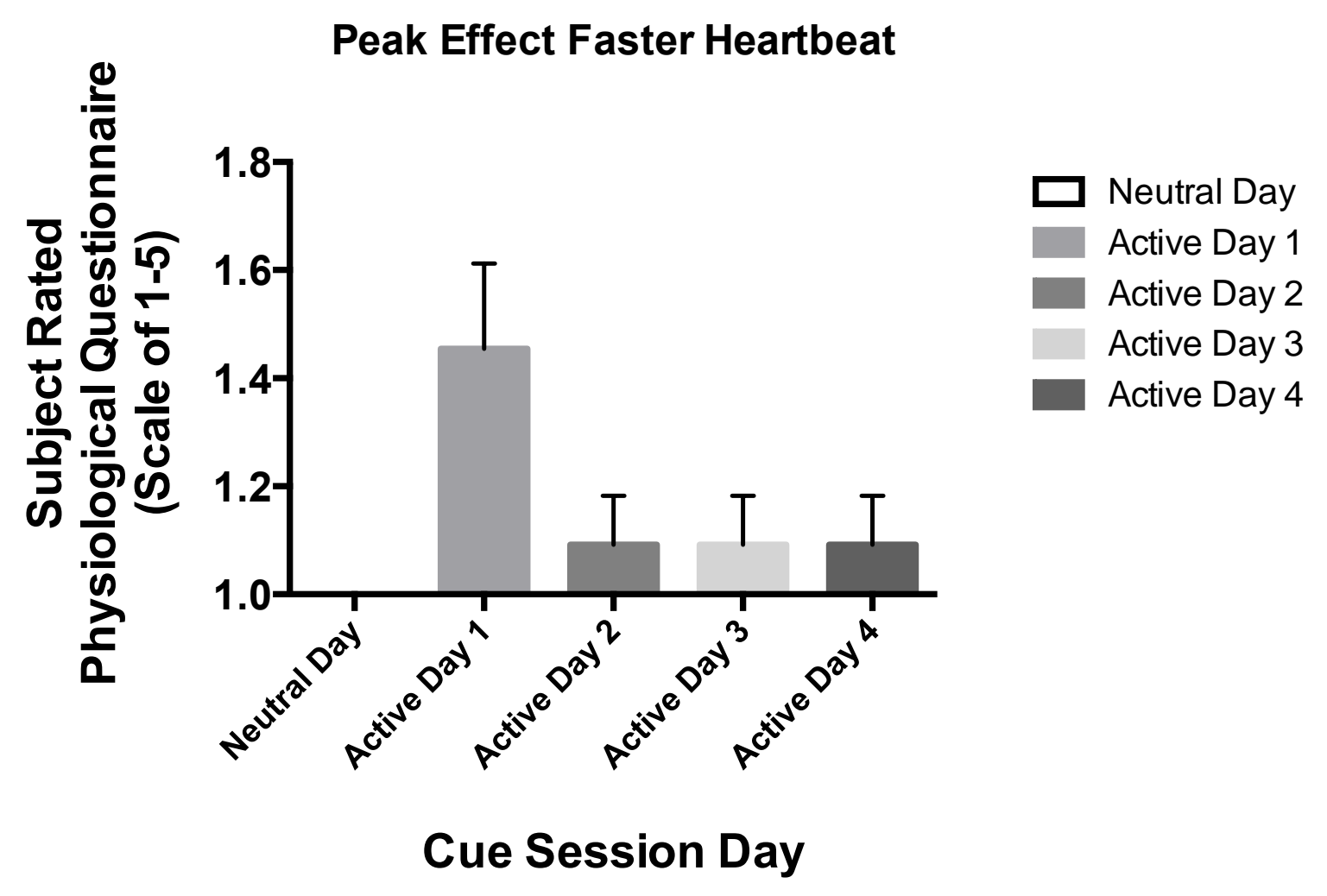

Copyright $\odot$ Jessica S. Fogel 2015 


\section{Chapter Seven: Conclusion}

The purpose of the present protocol was to test whether a cue reactivity procedure could elicit craving responses in a within-subjects laboratory setting. Additionally, the protocol aimed to see whether craving responses could be sustained across multiple experimental laboratory sessions.

It was hypothesized that exposure to cannabis cues would produce more robust craving responses than exposure to neutral cues in daily cannabis smokers in a within-subjects design. It was also hypothesized that subject-rated craving responses to cannabis cues would be sustained across multiple cannabis cue exposure sessions.

Results showed that initial cannabis cue exposure significantly increased subjective responses of craving compared with neutral cue exposure. These data are in agreement with previous research demonstrating increased subjective ratings of craving following drug cue exposure (Lundahl et al., 2011; Nickerson et al., 2011; Gray et al., 2008, 2011; Bordnick et al., 2009; McRae-Clark et al., 2011). Contrary to the hypothesis, the increased craving responses following cannabis cue exposure were not maintained across sessions (i.e., days 2-4). In recent study by Lundahl and Greenwald (2015), repeated cue exposures successfully elicited increased craving responses across multiple session days. A main difference between these studies is that Lundahl and Greenwald (2015) administered varying doses of oral THC prior to cue exposure, whereas this study did not. The Lundahl analysis focused on the effects of differential oral THC pretreatment on cannabis craving across multiple sessions. In contrast, the present study focused on the effects of session day on craving responses.

No significant differences were found on physiological measures (i.e., blood pressure and heart rate) following cannabis cue conditions relative to the neutral cue condition. The failure to detect changes in heart rate and blood pressure was expected. These data are consistent with previous findings (Lundahl et al., 2011; Gray et al., 2008; Nickerson et al., 2011) that did not detect cardiovascular physiological changes following cannabis cues relative to neutral cues. 
Initial cannabis cue exposure did however significantly increased subject-rated physiological response of "Faster Heartbeat." Subjects reported increased awareness of a faster heartbeat during the time they were handling the cannabis cue objects relative to the neutral cue objects. This outcome is consistent with classical conditioning theory. According to the classical conditioning model, conditioned stimuli such as drug cues will, over time, elicit drug-related physiological responses because of their repeated pairings with drug use.

Despite this subjective report of increased heartbeat, there were no actual increases in physiological measures of heart rate following cannabis cue exposure. One possible explanation could be that subjects detected a slight increase in heart rate that was not statistically significant. A second possible explanation could be that the physiological measure of heart rate was done at the end of the time point following the completion of the Subject-Rated Physiological Questionnaire, MCQ, and VAS. This one to two minute time lapse between the Subject-Rated Physiological Questionnaire and the physiological assessment might account for why the physiological change in heart rate was not detected. Future studies might seek to assess physiological measures closer to the completion of the cue exposure.

No significant differences were found on type of cue exposure session for any of the four MCQ subscales. The failure to observe cue-induced changes in MCQ ratings is inconsistent with previous studies. Previous research has demonstrated an increase in subjective ratings on the MCQ following active cannabis cue exposure (Lundahl et al., 2011; 2015; Gray et al., 2008; McRae-Clark et al., 2011). One possible explanation for this discrepancy could be due to differences of the cannabis cues used. For example, Gray and colleagues (2008) had participants "flick" a lighter during the tactile cue presentation, allowing for a more active involvement with the cannabis cues. Previous studies have also included olfactory cues and asked participants to smell a cannabis cigarette during cannabis cue exposure (Gray et al., 2008; Lundahl et al., 2011). These differences may have led to differences in subject-rated impact and incentive salience attributed to the cannabis cues. 
Several limitations should be considered. At no point during the study were subjects given access to smoke cannabis. Cannabis administration following cue exposure might have increased the salience of the cannabis cues. This in turn might have resulted in greater subjective craving responses following cannabis cue exposure. A second limitation of this study is the repetitive nature of the cannabis cue conditions. Previous research has focused on craving responses in single laboratory sessions. To our knowledge, this is the first study to examine the effects of multiple cue exposure sessions on cannabis craving. Participants in the present study were shown the same objects and video clip during each of the four cannabis cue exposure conditions. Subjects could have become sensitized to the repeated cannabis cue objects over time. This could explain the decrease in craving responses following the initial cannabis cue condition (i.e., days 2-4).

Another limitation was the lack of variability of cannabis paraphernalia during the cannabis cue exposure. Cannabis paraphernalia presented during the cannabis cue exposure condition consisted of a rolled joint, pipe, lighter, and rolling papers. The video clip involved someone rolling a joint and someone smoking a pipe. Since type of smoking preference is so varied (pipe, water pipe, blunt, joint, etc.), capturing a broader array of smoking preferences may tap into a more specific individualized cue responses.

Another possible limitation was the characteristics of the subjects enrolled in the study. Subjects recruited for the study were high functioning. The majority had full-time jobs, some had children, and some were enrolled as full time students. The majority of the subjects enrolled incorporated cannabis smoking into their otherwise full, daily routine. Cannabis cue exposure might differentially impact subjects who smoke cannabis multiple times throughout the day compared with subjects who, for example, smoke cannabis once a day or before they go to sleep. Previous research has shown differences in subjective responses to $\Delta^{9}$-THC between frequent and infrequent cannabis users (Kirk and De Wit, 1999). Although subjects in the present study were required to smoke cannabis at least 25 days per month, subjects varied in the daily amount of 
cannabis smoked, ranging from 1 to 6 times per day. Additionally, subjects in the present study reported lifetime cannabis use ranging from 2 years to 13 years. Future research should explore both daily and lifetime differences in cannabis use patterns as it relates to craving and cue exposure.

Future research should use more salient cannabis cues during the active drug cue exposure. For example, using a cannabis that is filled with actual cannabis may increase craving responses since it would have a more realistic look, feel, and smell than using a cannabis-like substitute. The closer laboratory cue exposure conditions can get to real world drug taking behavior, the greater likelihood craving responses will be increased. Additionally, future cue exposure studies should look to individualize cue exposure conditions and try to make laboratory conditions mimic subjects' real world drug taking situations as closely as possible.

There is limited research in the field directly linking cannabis craving with drug taking behavior. Craving has been associated with continued substance use and relapse during quit attempts in the natural environment. The present study was designed to be the first of a larger three-phase study. The purpose of the initial phase was to establish a within-subjects laboratory procedure where drug cues would elicit increased craving responses. The second phase is designed to establish causation between drug craving and relapse through a self-administration paradigm. The third phase of the study is designed to use the established procedure to quickly screen pharmacotherapies for CUDs. A better understanding of the factors that contribute to continued drug use despite quit attempts is important because such an understanding will help to develop models and procedures for the evaluation of behavioral and pharmacological therapies for treatment.

Copyright $@$ Jessica S. Fogel 2015 
Appendix A.

Cannabis Use Calendar

Have you ever used marijuana? ___ Yes ___ No

How have you used marijuana? Oral Smoking

Which method was most typical?

On the calendar, please circle the days that you used marijuana during the past 4 weeks and indicate how many times that you used marijuana on that day:

\begin{tabular}{|c|c|c|c|c|c|c|}
\hline Sun & Mon & Tue & Wed & Thu & Fri & Sat \\
\hline Sun & Mon & Tue & Wed & Thu & Fri & Sat \\
\hline Sun & Mon & Tue & Wed & Thu & Fri & Sat \\
\hline Sun & Mon & Tue & Wed & Thu & Fri & Sat \\
\hline Sun & Mon & Tue & Wed & Thu & Fri & Sat \\
\hline
\end{tabular}

How many days in the last year have you used marijuana?

If you have not used marijuana in the past year, when was your last use?

Which of the following best describes your typical use of marijuana:

non-medical (e.g., to party, to get high, to relax)?

Identify reason

prescribed by your doctor for a medical purpose?

Identify medical purpose

Has your marijuana use ever been a problem for you or for others?

Yes

No

If Yes, explain 


\section{Appendix B.}

\section{Sign-In Questionnaire}

1. How many hours of sleep did you get last night?

2. Have you used any nicotine products in the last 24 hours? Yes No

If you answered "yes", how many cigarettes have you used in the last 24 hours?

3. Have you had any alcohol in the last 12 hours? $\quad$ Yes No

If you answered "yes", at what time did you have your last drink?

4. Have you had any cannabis in the last 24 hours? $\quad$ Yes No

If you answered "yes", at what time did you last use cannabis?

5. Have you had any caffeinated beverages today? $\quad$ Yes No

If you answered "yes", at what time did you drink your last caffeinated beverage?

6. Have you taken any medications (either prescription or over the counter) or used any illicit drugs since your last session? Yes No

If you answered "yes", what were the medications and when did you take them?

7. Have you been ill since your last session?

Yes No

If you answered “yes”, please explain:

8. Have you experienced any changes in your usual routine since your last session?

Yes No

If you answered "yes", please explain:

9. If female, when was the start date of your last menstrual cycle? 
Appendix C.

Study Run Sheet

\begin{tabular}{|c|c|c|c|c|c|c|c|}
\hline \multirow{2}{*}{\multicolumn{2}{|c|}{$\begin{array}{l}\text { Study day } \\
\text { Type of Cue }\end{array}$}} & Practice & 1 & 2 & 3 & 4 & 5 \\
\hline & & & & & & & \\
\hline \multicolumn{2}{|c|}{ Date } & & & & & & \\
\hline \multicolumn{8}{|c|}{ Setup Materials: } \\
\hline \multicolumn{8}{|c|}{ set-up session computer } \\
\hline \multicolumn{8}{|c|}{ consent form } \\
\hline \multicolumn{8}{|c|}{ urine collection cup } \\
\hline \multicolumn{8}{|c|}{ pregnancy test } \\
\hline \multicolumn{8}{|c|}{ Check-in procedure } \\
\hline \multicolumn{8}{|c|}{ collect keys, watch, phone } \\
\hline \multicolumn{8}{|c|}{ smoke break $(\mathrm{Y} / \mathrm{N})$} \\
\hline \multicolumn{8}{|c|}{ field sobriety test } \\
\hline \multicolumn{2}{|c|}{ BAL } & $\%$ & $\%$ & $\%$ & $\%$ & $\%$ & $\%$ \\
\hline \multicolumn{2}{|l|}{$\mathrm{CO}$} & ppm & ppm & ppm & ppm & ppm & $\mathrm{ppm}$ \\
\hline \multicolumn{2}{|c|}{ weight } & lbs. & lbs. & lbs. & lbs. & lbs. & lbs. \\
\hline \multicolumn{8}{|c|}{ sign in questionnaire } \\
\hline \multicolumn{7}{|c|}{ urine screen (to run: negative } & \\
\hline \multicolumn{8}{|c|}{$\begin{array}{l}\text { pregnancy screen (to run: } \\
\text { negative) }\end{array}$} \\
\hline \multirow[t]{7}{*}{ 0:00 } & $\begin{array}{l}\text { Assessment } 1 \\
\text { (record start time) }\end{array}$ & & & & & & \\
\hline & BP & $\mathrm{mmHg}$ & $\mathrm{mmHg}$ & $\mathrm{mmHg}$ & $\mathrm{mmHg}$ & $\mathrm{mmHg}$ & $\mathrm{mmHg}$ \\
\hline & HR & bpm & bpm & bpm & bpm & bpm & bpm \\
\hline & Cue Exposure & & & & & & \\
\hline & $\begin{array}{l}\text { Assessment } 2 \\
\text { (record start time) }\end{array}$ & & & & & & \\
\hline & $\mathrm{BP}$ & $\mathrm{mmHg}$ & $\mathrm{mmHg}$ & $\mathrm{mmHg}$ & $\mathrm{mmHg}$ & $\mathrm{mmHg}$ & $\mathrm{mmHg}$ \\
\hline & $\mathrm{HR}$ & bpm & bpm & bpm & bpm & bpm & bpm \\
\hline \multirow[t]{3}{*}{ 0:30 } & $\begin{array}{l}\text { Assessment } 3 \\
\text { (record start time) }\end{array}$ & & & & & & \\
\hline & $\mathrm{BP}$ & $\mathrm{mmHg}$ & $\mathrm{mmHg}$ & $\mathrm{mmHg}$ & $\mathrm{mmHg}$ & $\mathrm{mmHg}$ & $\mathrm{mmHg}$ \\
\hline & HR & bpm & bpm & bpm & bpm & bpm & bpm \\
\hline \multirow[t]{3}{*}{ 1:00 } & $\begin{array}{l}\text { Assessment } 4 \\
\text { (record start time) }\end{array}$ & & & & & & \\
\hline & $\mathrm{BP}$ & $\mathrm{mmHg}$ & $\mathrm{mmHg}$ & $\mathrm{mmHg}$ & $\mathrm{mmHg}$ & $\mathrm{mmHg}$ & $\mathrm{mmHg}$ \\
\hline & HR & bpm & bpm & $\mathrm{bpm}$ & $\mathrm{bpm}$ & bpm & $\mathrm{bpm}$ \\
\hline
\end{tabular}




\begin{tabular}{|l|l|l|l|l|l|l|l|}
\hline Check-Out Procedure & & & & & & \\
\hline $\begin{array}{l}\text { return keys, watch, } \\
\text { cell phone }\end{array}$ & & & & & & \\
\hline back-up data & & & & & & \\
\hline & Up date earnings sheet & & & & & & \\
\hline
\end{tabular}




\section{Appendix D. \\ Marijuana Craving Questionnaire - Short Form}

Indicate how strongly you agree or disagree with each of the following statements by selecting a number between 1 (STRONGLY DISAGREE) and 7 (STRONGLY AGREE). The closer your selection to one end or the other indicates the strength of your agreement or disagreement. If you don't agree or disagree with a statement, select the mid-point number 4. Please complete every item. We are interested in how you are thinking or feeling right now as you are filling out the questionnaire. When you are done, click the "Next" button.

\section{Please answer the following questions based on how you are feeling RIGHT NOW:}

1. Smoking cannabis would be pleasant right now

STRONGLY DISAGREE $:$ $:$ :__ STRONGLY AGREE

2. I could not easily limit how much cannabis I smoked right now STRONGLY DISAGREE : : : : STRONGLY AGREE

3. Right now, I am making plans to use cannabis

STRONGLY DISAGREE : :___ STRONGLY AGREE

4. I would feel more in control of things right now if I could smoke cannabis STRONGLY DISAGREE $:$ : : $:$ :___ STRONGLY AGREE

5. Smoking cannabis would help me sleep better at night STRONGLY DISAGREE : $:$ $:$ :__ STRONGLY AGREE

6. If I smoked cannabis right now, I would feel less tense STRONGLY DISAGREE : :__ STRONGLY AGREE

7. I would not be able to control how much cannabis I smoked if I had some here STRONGLY DISAGREE STRONGLY AGREE

8. It would be great to smoke cannabis right now STRONGLY DISAGREE $:$ $:$ : :___ STRONGLY AGREE

9. I would feel less anxious if I smoked cannabis right now STRONGLY DISAGREE : $:$ :__ STRONGLY AGREE

10. I need to smoke cannabis now

STRONGLY DISAGREE : : $:$ : STRONGLY AGREE 
11. If I were smoking cannabis right now, I would feel less nervous STRONGLY DISAGREE __________________$:{ }_{\ldots}: \ldots \_$___ STRONGLY AGREE 12. Smoking cannabis would make me content.

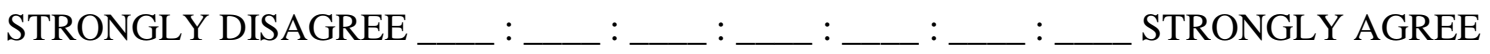




\title{
Appendix E. \\ Visual Analog Scale
}

\begin{abstract}
A series of questions will be individually presented on the computer screen. Use the mouse to move the indicator to the place on the line, labeled "Not at all" on the left and "Extremely" on the right, which best indicates how you feel at the moment, and then click the mouse button. You can change your answer by repositioning the indicator along the line and clicking again. When you are done, click the "Next" button.
\end{abstract}

Please answer the following questions based on how you are feeling RIGHT NOW:

I feel...

Sedated

Stimulated

Nauseated

Shaky or Jittery

Restless

Dizzy

Difficulty Concentrating

Anxious

Nervous

I have a craving for...

Alcohol

Tobacco

Marijuana

Cocaine

Opiates 


\section{Appendix F. \\ Subject-Rated Physiological Questionnaire}

Indicate how aware you were of the following symptoms while handling the objects by selecting a number between 1 (NOT AT ALL) and 5 (ALL OF THE TIME). The closer your selection to one end or the other indicates the strength of your awareness. Please complete every item. We are interested in how you were thinking or feeling during the time you were handling the objects as you are filling out the questionnaire. When you are done, click the "Next" button.

During the time you were handling the object, how much of the time were you aware of each? Click on the NEXT button to go to the next statement.

1. Faster heart rate

NOT AT ALL $:$ : $:$ ALL OF THE TIME

2. Rapid breathing

NOT AT ALL : : $:$ ALL OF THE TIME

3. Sweating hands

NOT AT ALL : : ALL OF THE TIME

4. Heavy feeling in the stomach

NOT AT ALL $:$ : : ALL OF THE TIME

5. Loud pounding heart

NOT AT ALL

6. Tensed muscles
NOT AT ALL

7. Cold hands $:$ : ALL OF THE TIME

NOT AT ALL : :__ ALL OF THE TIME

8. Feeling flushed or hot

NOT AT ALL : : ALL OF THE TIME

9. Salivating more

NOT AT ALL : : $:$ ALL OF THE TIME

10. Trembling NOT AT ALL : : : : ALL OF THE TIME

11. Dry mouth

NOT AT ALL $:$ : : : ALL OF THE TIME 


\section{References}

Allsop, D. J., et al. (2014). Nabiximols as an agonist replacement therapy during cannabis withdrawal: a randomized clinical trial. JAMA Psychiatry, 71, 281-291.

American Psychiatric Association. (2013). Diagnostic and Statistical Manual of Mental Disorders (5th ed.). Washington, DC.

Ashton, C. H. (2001). Pharmacology and effects of cannabis: a brief review.The British Journal of Psychiatry, 178(2), 101-106.

Balter, R. E., Cooper, Z. D., \& Haney, M. (2014). Novel pharmacologic approaches to treating cannabis use disorder. Current addiction reports, 1(2), 137-143.

Bordnick, P. S., Copp, H. L., Traylor, A., Graap, K. M., Carter, B. L., Walton, A., \& Ferrer, M. (2009). Reactivity to cannabis cues in virtual reality environments. Journal of Psychoactive Drugs, 41(2), 105-112.

Borgwardt, S. J., Allen, P., Bhattacharyya, S., Fusar-Poli, P., Crippa, J. A., Seal, M. L., ... \& McGuire, P. K. (2008). Neural basis of $\Delta$-9-tetrahydrocannabinol and cannabidiol: effects during response inhibition. Biological psychiatry, 64(11), 966-973.

Brook, J. S., Lee, J. Y., Finch, S. J., Seltzer, N., \& Brook, D. W. (2013). Adult Work Commitment, Financial Stability, and Social Environment as Related to Trajectories of Marijuana Use Beginning in Adolescence. Substance Abuse : Official Publication of the Association for Medical Education and Research in Substance Abuse, 34(3), 298-305.

Budney, A. J., Higgins, S. T., Radonovich, K. J., \& Novy, P. L. (2000). Adding voucher-based incentives to coping skills and motivational enhancement improves outcomes during treatment for marijuana dependence. Journal of consulting and clinical psychology, 68(6), 1051.

Budney, A. J., Moore, B. A., Rocha, H. L., \& Higgins, S. T. (2006). Clinical trial of abstinencebased vouchers and cognitive-behavioral therapy for cannabis dependence. Journal of Consulting and Clinical Psychology, 74(2), 307.

Budney, A. J., Roffman, R., Stephens, R. S., \& Walker, D. (2007a). Marijuana dependence and its treatment. Addiction science \& clinical practice, 4(1), 4.

Budney, A. J., Vandrey, R. G., Hughes, J. R., Moore, B. A., \& Bahrenburg, B. (2007b). Oral delta-9-tetrahydrocannabinol suppresses cannabis withdrawal symptoms. Drug and Alcohol Dependence, 86(1), 22-29.

Buffalari, D. M., Feltenstein, M. W., \& See, R. E. (2013). The effects of varied extinction procedures on contingent cue-induced reinstatement in Sprague-Dawley rats. Psychopharmacology, 230(2), 319-327.

Carter, B. L., \& Tiffany, S. T. (1999). Meta-analysis of cue-reactivity in addiction research. Addiction, 94, 327-340. 
Cooper, Z. D., \& Haney, M. (2010). Opioid antagonism enhances marijuana's effects in heavy marijuana smokers. Psychopharmacology, 211(2), 141-148.

Coffey, C., Carlin, J.B., Degenhardt, L., Lynskey, M., Sanci, L., \& Patton, G.C. (2002). Cannabis dependence in young adults: An Australian population study. Addiction 97(2):187-194.

Cornelius, J. R., Chung, T., Martin, C., Wood, D. S., \& Clark, D. B. (2008). Cannabis withdrawal is common among treatment-seeking adolescents with cannabis dependence and major depression, and is associated with rapid relapse to dependence. Addictive

Behaviors, 33(11), 1500-1505.

Childress, A. R., Hole, A. V., Ehrman, R. N., Robbins, S. J., McLellan, A. T., \& O’Brien, C. P. (1993). Cue reactivity and cue reactivity interventions in drug dependence. NIDA research monograph, 137, 73-73.

Copeland, J., Swift, W., Roffman, R., \& Stephens, R. (2001). A randomized controlled trial of brief cognitive-behavioral interventions for cannabis use disorder. Journal of Substance Abuse Treatment, 21(2), 55-64.

Crombag, H. S., \& Shaham, Y. (2002). Renewal of drug seeking by contextual cues after prolonged extinction in rats. Behavioral neuroscience, 116(1), 169.

Doweiko, H. E. (2015). Marijuana abuse and addiction. Concepts of chemical dependency (9th ed.). California: Brooks/Cole.

Downey, L. A., King, R., Papafotiou, K., Swann, P., Ogden, E., Boorman, M., \& Stough, C. (2013). The effects of cannabis and alcohol on simulated driving: influences of dose and experience. Accident Analysis \& Prevention, 50, 879-886.

Drummond, D. C., Litten, R. Z., Lowman, C., \& Hunt, W. A. (2000). Craving research: Future directions. Addiction, 95(8s2), 247-255.

ElSohly, M. A., \& Slade, D. (2005). Chemical constituents of marijuana: the complex mixture of natural cannabinoids. Life sciences, 78(5), 539-548.

Field, M., \& Cox, W. M. (2008). Attentional bias in addictive behaviors: a review of its development, causes, and consequences. Drug and alcohol dependence,97(1), 1-20.

Fergusson, D. M., \& Boden, J. M. (2008). Cannabis use and later life outcomes. Addiction, 103(6), 969-976.

Ferguson, S. G., \& Shiffman, S. (2009). The relevance and treatment of cue-induced cravings in tobacco dependence. Journal of substance abuse treatment, 36(3), 235-243.

Fox, H. C., Bergquist, K. L., Hong, K. I., \& Sinha, R. (2007). Stress-Induced and Alcohol CueInduced Craving in Recently Abstinent Alcohol-Dependent Individuals. Alcoholism: Clinical and Experimental Research, 31(3), 395-403.

Gaoni, Y., \& Mechoulam, R. (1964). Isolation, structure, and partial synthesis of an active constituent of hashish. Journal of the American Chemical Society,86(8), 1646-1647. 
Gray, K. M., LaRowe, S. D., \& Upadhyaya, H. P. (2008). Cue reactivity in young marijuana smokers: a preliminary investigation. Psychology of Addictive Behaviors, 22(4), 582.

Gray, K. M., LaRowe, S. D., Watson, N. L., \& Carpenter, M. J. (2011). Reactivity to in vivo marijuana cues among cannabis-dependent adolescents. Addictive behaviors, 36(1), 140143.

Gray, K. M., Carpenter, M. J., Baker, N. L., DeSantis, S. M., Kryway, E., Hartwell, K. J., McRae-Clark, A. L., \& Brady, K. T. (2012). A double-blind randomized controlled trial of $\mathrm{N}$-acetylcysteine in cannabis-dependent adolescents. American Journal of Psychiatry, 169(8), 805-812.

Grotenhermen, F., Leson, G., Berghaus, G., Drummer, O. H., Krüger, H. P., Longo, M., Moskowitz, H., Perrine, B., Ramaekers, G., Smiley, A., \& Tunbridge, R. (2007). Developing limits for driving under cannabis. Addiction, 102(12), 1910-1917.

Hall, W. D. (1998). Cannabis use and psychosis. Drug and alcohol review, 17(4), 433-444.

Haney, M., Comer, S. D., Ward, A. S., Foltin, R. W., \& Fischman, M. W. (1997). Factors influencing marijuana self-administration by humans. Behavioural pharmacology.

Haney, M., Hart, C. L., Vosburg, S. K., Nasser, J., Bennett, A., Zubaran, C., \& Foltin, R. W. (2004). Marijuana withdrawal in humans: effects of oral THC or divalproex. Neuropsychopharmacology, 29(1), 158-170.

Haney, M., Hart, C. L., Vosburg, S. K., Comer, S. D., Reed, S. C., \& Foltin, R. W. (2008). Effects of THC and lofexidine in a human laboratory model of marijuana withdrawal and relapse. Psychopharmacology, 197(1), 157-168.

Haney, M., Bedi, G., Cooper, Z. D., Glass, A., Vosburg, S. K., Comer, S. D., \& Foltin, R. W. (2013a). Predictors of marijuana relapse in the human laboratory: robust impact of tobacco cigarette smoking status. Biological psychiatry, 73(3), 242-248.

Haney, M., Cooper, Z. D., Bedi, G., Vosburg, S. K., Comer, S. D., \& Foltin, R. W. (2013b). Nabilone decreases marijuana withdrawal and a laboratory measure of marijuana relapse. Neuropsychopharmacology, 38(8), 1557-1565.

Haney, M., Ramesh, D., Glass, A., Pavlicova, M., Bedi, G., \& Cooper, Z. D. (2015). Naltrexone Maintenance Decreases Cannabis Self Administration and Subjective Effects in Daily Cannabis Smokers. Neuropsychopharmacology.

Hart, C. L., Haney, M., Ward, A. S., Fischman, M. W., \& Foltin, R. W. (2002). Effects of oral THC maintenance on smoked marijuana self-administration. Drug and alcohol dependence, 67(3), 301-309.

Heishman, S. J., Singleton, E. G., \& Liguori, A. (2001). Marijuana Craving Questionnaire: development and initial validation of a self-report instrument. Addiction, 96(7), 10231034. 
Huestis, M. A., Gorelick, D. A., Heishman, S. J., Preston, K. L., Nelson, R. A., Moolchan, E. T., \& Frank, R. A. (2001). Blockade of effects of smoked marijuana by the CB1-selective cannabinoid receptor antagonist SR141716. Archives of General Psychiatry, 58(4), 322328.

Huestis, M. A. (2007a). Human cannabinoid pharmacokinetics. Chemistry \& biodiversity, 4(8), 1770-1804.

Huestis, M. A., Boyd, S. J., Heishman, S. J., Preston, K. L., Bonnet, D., Le Fur, G., \& Gorelick, D. A. (2007b). Single and multiple doses of rimonabant antagonize acute effects of smoked cannabis in male cannabis users. Psychopharmacology, 194(4), 505515.

Hyman, S. M., Fox, H., Hong, K. I. A., Doebrick, C., \& Sinha, R. (2007). Stress and drug-cueinduced craving in opioid-dependent individuals in naltrexone treatment. Experimental and clinical psychopharmacology, 15(2), 134.

Iverson, L. L., Iversen, S. D., Bloom, F. E., \& Roth, H. R. (2009a). Other interneuronal signals. Introduction to Neuropsychopharmacology. New York: Oxford University Press

Johns, A. (2001). Psychiatric effects of cannabis. The British Journal of Psychiatry, 178(2), 116122.

Julien, R. M., Advokat, C. D., \& Comaty, J. E. (2011) Cannabinoid Agonists and Antagonists. A primer of drug addiction (11th ed.). New York: Worth Publishers

Kearns, D. N., Tunstall, B. J., \& Weiss, S. J. (2012). Deepened extinction of cocaine cues. Drug and alcohol dependence, 124(3), 283-287.

Khan, R., Morrow, L. J., \& McCarron, R. M. (2009). How to manage medical complications of the 5 most abused substances. Current Psychiatry, 8(11), 35.

Kirk, J. M., \& De Wit, H. (1999). Responses to oral $\Delta$ 9-tetrahydrocannabinol in frequent and infrequent marijuana users. Pharmacology Biochemistry and Behavior, 63(1), 137142.

Koob, G. F. (2006). The neurobiology of addiction: a neuroadaptational view relevant for diagnosis. Addiction, 101(s1), 23-30.

Lee, J. H., Kwon, H., Choi, J., \& Yang, B. H. (2007). Cue-exposure therapy to decrease alcohol craving in virtual environment. CyberPsychology \& Behavior,10(5), 617-623.

Levin, F. R., Mariani, J. J., Brooks, D. J., Pavlicova, M., Cheng, W., \& Nunes, E. V. (2011). Dronabinol for the treatment of cannabis dependence: a randomized, double-blind, placebo-controlled trial. Drug and alcohol dependence, 116(1), 142-150.

Lile J. A., Kelly T.H., Hays L.R. (2010a) The reinforcing, self-reported, performance and physiological effects of $\Delta^{9}$-THC, triazolam, hydromorphone and methylphenidate in cannabis users. Behavioural Pharmacology, 21: 29-38. 
Lile, J. A., Kelly, T. H., \& Hays, L. R. (2010b). Substitution profile of the cannabinoid agonist nabilone in human subjects discriminating $\Delta^{9}$-tetrahydrocannabinol. Clinical Neuropharmacology, 33, 235. 242.

Lile, J. A., Kelly, T. H., \& Hays, L. R. (2011). Separate and combined effects of the cannabinoid agonists nabilone and $\Delta$ 9-THC in humans discriminating $\triangle 9$-THC. Drug and alcohol dependence, $116(1), 86-92$.

Lile, J. A., Kelly, T. H., \& Hays, L. R. (2012). Separate and combined effects of the GABA B agonist baclofen and $\Delta 9$-THC in humans discriminating $\Delta$ 9-THC.Drug and alcohol dependence, 126(1), 216-223.

Lundahl, L. H., \& Johanson, C. E. (2011). Cue-induced craving for marijuana in cannabisdependent adults. Experimental and clinical psychopharmacology,19(3), 224.

Lundahl, L. H., \& Greenwald, M. K. (2015). Effect of oral THC pretreatment on marijuana cueinduced responses in cannabis dependent volunteers. Drug and alcohol dependence, 149, 187-193.

Macleod, J., Oakes, R., Copello, A., Crome, I., Egger, M., Hickman, M., Oppenkowski, T., Stokes-Lampard, H., \& Smith, G. D. (2004). Psychological and social sequelae of cannabis and other illicit drug use by young people: a systematic review of longitudinal, general population studies. The Lancet, 363(9421), 1579-1588.

Marissen, M. A., Franken, I. H., Blanken, P., van Den Brink, W., \& Hendriks, V. M. (2006). Cue exposure therapy for the treatment of opiate addiction: results of a randomized controlled clinical trial. Psychotherapy and psychosomatics,76(2), 97-105.

Marlatt, G. A. (1990). Cue exposure and relapse prevention in the treatment of addictive behaviors. Addictive behaviors, 15(4), 395-399.

Mason, B. J., Crean, R., Goodell, V., Light, J. M., Quello, S., Shadan, F., ... \& Rao, S. (2012). A proof-of-concept randomized controlled study of gabapentin: effects on cannabis use, withdrawal and executive function deficits in cannabis-dependent adults. Neuropsychopharmacology, 37(7), 1689-1698.

Maykut, M. O. (1985) Health consequences of acute and chronic marijuana use. Progress in Neuropsychopharmacology and Biological Psychiatry, 9, 209-238.

McLaren, J., Swift, W., Dillon, P., \& Allsop, S. (2008). Cannabis potency and contamination: a review of the literature. Addiction, 103(7), 1100-1109.

McGilveray, I. J. (2005). Pharmacokinetics of cannabinoinds. Pain Research and Management $10(A), 15 A-22 A$.

McRae, A. L., Budney, A. J., \& Brady, K. T. (2003). Treatment of marijuana dependence: a review of the literature. Journal of Substance Abuse Treatment,24(4), 369-376.

McRae-Clark, A. L., Carter, R. E., Price, K. L., Baker, N. L., Thomas, S., Saladin, M. E., ... \& Brady, K. T. (2011). Stress-and cue-elicited craving and reactivity in marijuanadependent individuals. Psychopharmacology, 218(1), 49-58. 
Meier, M. H., Caspi, A., Ambler, A., Harrington, H., Houts, R., Keefe, R. S., ... \& Moffitt, T. E. (2012). Persistent cannabis users show neuropsychological decline from childhood to midlife. Proceedings of the National Academy of Sciences, 109(40), E2657-E2664.

Munro, S., Thomas, K. L., \& Abu-Shaar, M. (1993). Molecular characterization of a peripheral receptor for cannabinoids.

National Institute on Drug abuse. Research Report Series: Marijuana. (April 2015). From http://www.drugabuse.gov/publications/research-reports/marijuana

Nickerson, L. D., Ravichandran, C., Lundahl, L. H., Rodolico, J., Dunlap, S., Trksak, G. H., \& Lukas, S. E. (2011). Cue reactivity in cannabis-dependent adolescents. Psychology of Addictive Behaviors, 25(1), 168.

Pertwee, R. G. (1998). Pharmacological, physiological and clinical implications of the discovery of cannabinoid receptors. Biochemical Society transactions,26(2), 267-272.

Pineda, J., Ruiz-Ortega, J. A., \& Ugedo, L. (1997). Receptor reserve and turnover of alpha-2 adrenoceptors that mediate the clonidine-induced inhibition of rat locus coeruleus neurons in vivo. Journal of Pharmacology and Experimental Therapeutics, 281(2), 690698.

Pol, P., Liebregts, N., Brunt, T., Amsterdam, J., Graaf, R., Korf, D. J., ... \& Laar, M. (2014). Cross-sectional and prospective relation of cannabis potency, dosing and smoking behaviour with cannabis dependence: an ecological study.Addiction, 109(7), 1101-1109.

Robbins, S. J., Ehrman, R. N., Childress, A. R., \& O’Brien, C. P. (1992). Using cue reactivity to screen medications for cocaine abuse: A test of amantadine hydrochloride. Addictive Behaviors, 17, 491-499.

Santa Ana, E. J., Prisciandaro, J. J., Saladin, M. E., McRae-Clark, A. L., Shaftman, S. R., Nietert, P. J., \& Brady, K. T. (2015). D-cycloserine combined with cue exposure therapy fails to attenuate subjective and physiological craving in cocaine dependence. The American Journal on Addictions, 24(3), 217-224.

Sayette, M. A., Shiffman, S., Tiffany, S. T., Niaura, R. S., Martin, C. S., \& Schadel, W. G. (2000). The measurement of drug craving. Addiction, 95(8s2), 189-210.

Schoedel, K. A., et al. (2011). A randomized, double-blind, placebo-controlled, crossover study to evaluate the subjective abuse potential and cognitive effects of nabiximols oromucosal spray in subjects with a history of recreational cannabis use. Human Psychopharmacology, 26, 224-236.

Sidney, S. (2002). Cardiovascular consequences of marijuana use. The Journal of Clinical Pharmacology, 42(S1), 64S-70S.

Siegel, S., \& Ramos, B. (2002). Applying laboratory research: drug anticipation and the treatment of drug addiction. Experimental and Clinical Psychopharmacology, 10(3), 162. 
Silins, E., Horwood, L. J., Patton, G. C., Fergusson, D. M., Olsson, C. A., Hutchinson, D. M., Spry, E., Toumbourou, J. W., Degenhardt, L., Swift, W., Coffey, C., Tait, R. J., Letcher, P., Copeland, J., \& Mattick R. P. (2014). Young adult sequelae of adolescent cannabis use: an integrative analysis. The Lancet Psychiatry, 1(4), 286-293.

Steinberg, K.L.; Roffman, R.A.; Carroll, K.M.; McRee, B.; Babor, T.F.; Miller, M.; Kadden, R.; Duresky, D.; and Stephens, R. Brief Counseling for Marijuana Dependence: A Manual for Treating Adults. DHHS Publication No. (SMA) 05-4022. Rockville, MD: Center for Substance Abuse Treatment, Substance Abuse and Mental Health Services Administration, 2005.

Stephens, R. S., Roffman, R. A., \& Simpson, E. E. (1994). Treating adult marijuana dependence: a test of the relapse prevention model. Journal of consulting and clinical psychology, 62(1), 92.

Substance Abuse and Mental Health Services Administration, Center for Behavioral Health Statistics and Quality. The DAWN Report: Highlights of the 2011 Drug Abuse Warning Network (DAWN) Findings on Drug-Related Emergency Department Visits. Rockville, MD.

Substance Abuse and Mental Health Services Administration, Results from the 2013 National Survey on Drug Use and Health: Summary of National Findings, NSDUH Series H-48, HHS Publication No. (SMA) 14-4863. Rockville, MD: Substance Abuse and Mental Health Services Administration, 2014.

Taylor, J. R., Olausson, P., Quinn, J. J., \& Torregrossa, M. M. (2009). Targeting extinction and reconsolidation mechanisms to combat the impact of drug cues on addiction. Neuropharmacology, 56, 186-195.

Tiffany, S. T., Carter, B. L., \& Singleton, E. G. (2000). Challenges in the manipulation, assessment and interpretation of craving relevant variables.Addiction, 95(8s2), 177-187.

Tseng, A. H., \& Craft, R. M. (2004). CB(1) receptor mediation of cannabinoid behavioral effects in male and female rats. Psychopharmacology, 172, 25-30.

Vandrey, R., \& Haney, M. (2009). Pharmacotherapy for Cannabis Dependence. CNS drugs, 23(7), 543-553.

Vandrey, R., Stitzer, M. L., Mintzer, M. Z., Huestis, M. A., Murray, J. A., \& Lee, D. (2013). The dose effects of short-term dronabinol (oral THC) maintenance in daily cannabis users. Drug and alcohol dependence, 128(1), 64-70.

Van Os, J., Bak, M., Hanssen, M., Bijl, R. V., De Graaf, R., \& Verdoux, H. (2002). Cannabis use and psychosis: a longitudinal population-based study.American journal of epidemiology, 156(4), 319-327.

Weinstein, A. M., \& Gorelick, D. A. (2011). Pharmacological treatment of cannabis dependence. Current pharmaceutical design, 17(14), 1351.

Weiss, F. (2005). Neurobiology of craving, conditioned reward and relapse. Current opinion in pharmacology, 5(1), 9-19. 
Welch, S. P. (2005). The neurobiology of marijuana. In J. H. Lowinson, P. Ruiz, R. B. Millman, \& J. G. Langrod (Eds.), Substance abuse: A comprehensive textbook (4th ed.). New York: Lippincott Williams \& Wilkins.

Wölfling, K., Flor, H., \& Grüsser, S. M. (2008). Psychophysiological responses to drugassociated stimuli in chronic heavy cannabis use. European Journal of Neuroscience, 27(4), 976-983. 


\section{VITA}

Jessica S. Fogel

EDUCATION

2008 University of Michigan B.A., Psychology

RESEARCH EXPERIENCES

May 2010-June 2013

Research Assistant

Substance Use Research Center

New York State Psychiatric Institute

Columbia University Medical Center

October 2008-May 2010

Research Associate

Ethics Department

Saint Vincent's Catholic Medical Center

January 2008-June 2008

Data Management Lab Assistant

Addiction Research Center

University of Michigan

September 2007-

Research Assistant

December 2007

Department of Clinical and Developmental Psychology

University of Michigan

September 2007-

Research Assistant

December 2007

Department of Cultural and Social Psychology

University of Michigan

ADVISING ACTIVITIES

Undergraduate Students

Tyler Delong

Spring 2015

BIO 395: Independent Work in Biology

University of Kentucky College of Arts and Sciences

Inna Malyuk, B.A.

Summer 2014

University of Kentucky

Summer Training in Alcohol Research

Center for Drug Abuse Research Translation 
PROFESSIONAL ACTIVITIES

Memberships

Joined 2013

College on Problems of Drug Dependence

\title{
Awards
}

2014

2014-2015

\author{
Women and Gender Junior Investigator Travel Award \\ College on Problems of Drug Dependence Annual Meeting \\ San Juan, Puerto Rico \\ National Institute on Drug Abuse Predoctoral Training Fellowship \\ Department of Behavioral Science, University of Kentucky College \\ of Medicine
}

\section{RESEARCH \& INTELLECTUAL CONTRIBUTIONS}

\section{Publications}

Peer-Reviewed Original Research in Scientific Journals

4. Fogel JS, Kelly TH, Westgate PM, Lile JA (2014) Sex differences in the subjective effects of oral $\Delta^{9}$-THC in cannabis users. In submission.

3. Jansen LA, Fogel JS, Brubaker M (2013) Experimental philosophy, clinical intentions, and evaluative judgment. Cambridge Quarterly Journal of Health Care Ethics, 22: 126-135. PMID: 23507175.

2. Jansen LA, Appelbaum PS, Klein WK, Weinstein ND, Cook W, Fogel JS, Sulmasy DP (2011) Unrealistic optimism in early-phase oncology trials. IRB: Ethics and Human Research, 33: 1-8. PMID: 21314034.

1. Jansen LA, Fogel JS (2010) Ascribing intentions in clinical decision-making. Journal of Medical Ethics, 36: 2-6. PMID: 20026685.

\section{Book Chapters}

Lile JA, Fogel JS, Kelly TH (2014) The role of $\gamma$-aminobutyric acid in the interoceptive effects of oral $\Delta^{9}$-tetrahydrocannabinol in humans. In: Preedy VR, (ed), The Comprehensive Handbook of Cannabis Related Pathology.

\section{Abstract Presentations}

National/International

14. Fogel JS, Kelly T, Harvanko A, Lile J (2015). Effects of repeated cue exposure on cannabis craving. Poster presentation. Problems of Drug Dependence 2015: College on Problems of Drug Dependence $77^{\text {th }}$ Annual Scientific Meeting. Phoenix, Arizona

13. Harvanko AM, Martin CM, Fogel JS, Lile JA, Kelly TH (2015) A comparison of the behavioral effects of electronic and tobacco cigarettes following 24-hr tobacco deprivation. Poster presentation. Problems of Drug Dependence 2015: College on Problems of Drug Dependence $77^{\text {th }}$ Annual Scientific Meeting. Phoenix, Arizona 
12. Harvanko AM, Martin CM, Fogel JS, Lile JA, Kelly TH (2015) The abuse liability of electronic cigarettes as a function of nicotine dose. Poster presentation. American Psychological Association $123^{\text {th }}$ Annual Scientific Meeting, Division 28 Psychopharmacology and Substance Abuse Poster Session and NIDA/NIAA/APA (Divisions 28 and 50) Early Career Investigators Poster Session and Social Hour. Toronto, Canada

12. Harvanko AM, Martin CM, Fogel JS, Lile JA, Kelly TH (2015) A comparison of the selfreported effects of electronic and conventional cigarettes. Poster presentation. University of Kentucky Clinical and Translational Research Spring Conference 2015. Lexington, KY

11. Fogel JS, Kelly T, Charnigo R, Harvanko A, Lile J (2014) Predictors of the response to oral $\Delta^{9}$-THC in regular cannabis users: Focus on sex differences. Poster presentation. Problems of Drug Dependence 2014: College on Problems of Drug Dependence $76^{\text {th }}$ Annual Scientific Meeting. San Juan, Puerto Rico

10. Fogel JS, Kelly T, Charnigo R, Harvanko A, Lile J (2014) Sex differences in subjective and physiological responses to oral $\Delta^{9}$-THC in regular cannabis users. Poster presentation. University of Kentucky Clinical and Translational Research Spring Conference 2014. Lexington, KY

9. Lile J, Kelly T, Stoops W, Fogel JS, Harvanko A, Charnigo R, Hays L (2014) Cannabis selfadministration in the laboratory and use in the natural environment during outpatient tiagabine maintenance. Poster presentation. Problems of Drug Dependence 2014: College on Problems of Drug Dependence $76^{\text {th }}$ Annual Scientific Meeting. San Juan, Puerto Rico

8. Harvanko AM, Martin CM, Charnigo RJ, Fogel JS, Lile JA, Kelly TH (2014) Predicting the effects of d-amphetamine using measures of sensation seeking and impulsivity. Poster presentation. Problems of Drug Dependence 2014: College on Problems of Drug Dependence $76^{\text {th }}$ Annual Scientific Meeting. San Juan, Puerto Rico

7. Harvanko AM, Martin CM, Charnigo RJ, Fogel JS, Lile JA, Kelly TH (2014) The relationship between sensation seeking and impulsivity on d-amphetamine taking behavior. Poster presentation. University of Kentucky Clinical and Translational Research Spring Conference 2014. Lexington, KY

6. Kelly TH, Anderson A, Jenkins S, Harvanko A, Martin CA, Fogel JS, Joseph J, Lile JA (2014) d-Amphetamine effects and monetary incentive delay task performance: an fMRI study. Poster presentation. Problems of Drug Dependence 2014: College on Problems of Drug Dependence $76^{\text {th }}$ Annual Scientific Meeting. San Juan, Puerto Rico

5. Sullivan MA, Manubay JM, Vosburg SK, Jones JD, Cooper ZD, Fogel JS, Davidson JW, Comer SD (2013) Buprenorphine/naloxone for the treatment of prescription opioid abuse and chronic pain. Poster presentation. Problems of Drug Dependence 2013: College on Problems of Drug Dependence $75^{\text {th }}$ Annual Scientific Meeting. San Diego, CA 
4. Manubay JM, Davidson JW, Vosburg SK, Jones JD, Cooper ZD, Fogel JS, Comer SD, Sullivan MA (2013) Sex differences among opioid-abusing chronic pain patients in a clinical trial. Poster presentation. Problems of Drug Dependence 2013: College on Problems of Drug Dependence $75^{\text {th }}$ Annual Scientific Meeting. San Diego, CA

3. Mogali S, Askalsky P, Fogel JS, Madera G, Jones JD, Sullivan MA, Manubay JM, Comer SD (2013) The effects of minocycline on oxycodone-induced responses. Podium presentation. Experimental Biology 2013. Boston, MA

2. Comer SD, Bisaga A, Jones JD, Mogali S, Manubay JM, Sullivan MA, Vosburg SK, Cooper ZD, Roux P, Fogel JS, Shiffrin L (2012) Relationship between reactivity to heroinrelated cues, heroin craving, and heroin self-administration in buprenorphine-maintained heroin abusers. Poster presentation. American College of Neuropsychopharmacology 2012. Hollywood, FL

1. Manubay JM, Vosburg SK, Comer SD, Jones JD, Cooper ZD, Fogel JS, Sullivan MA (2011) Sex differences in patients with chronic pain and prescription opioid abuse during buprenorphine/naloxone maintenance. Poster presentation. Problems of Drug Dependence 2011: College on Problems of Drug Dependence $73^{\text {rd }}$ Annual Scientific Meeting. Hollywood, FL

\section{Sponsored Research Funding}

Principal Investigator

Active

Title: $\quad$ Effects of Environmental Cues on Cannabis Craving

PI: $\quad$ Jessica Fogel (faculty mentor: Joshua Lile, Ph.D.)

Source: $\quad$ Department of Behavioral Science, University of Kentucky College of Medicine Duration: $\quad 02 / 12 / 14-06 / 30 / 14$

Total Award: $\$ 3,120$ 